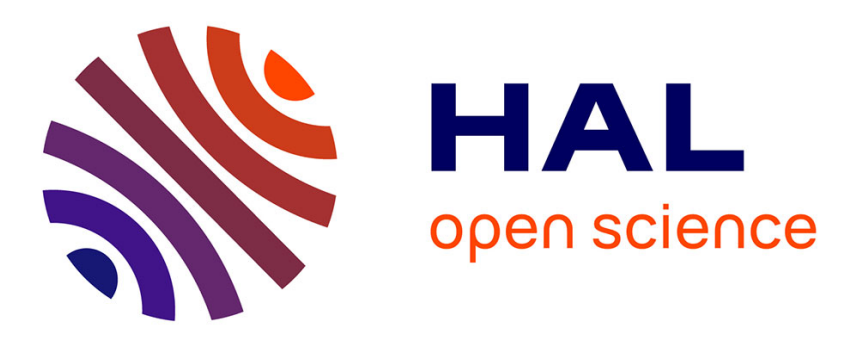

\title{
Complex Epitaxy of Tetragonal Tungsten Bronze K-Ta-Nb-O Nanorods
}

Valérie Demange, Quentin Simon, F. Gouttefangeas, Loïc Joanny, Maryline Guilloux-Viry

\section{- To cite this version:}

Valérie Demange, Quentin Simon, F. Gouttefangeas, Loïc Joanny, Maryline Guilloux-Viry. Complex Epitaxy of Tetragonal Tungsten Bronze K-Ta-Nb-O Nanorods. Crystal Growth \& Design, 2020, 20 (4), pp.2356-2366. 10.1021/acs.cgd.9b01501 . hal-02797038

\section{HAL Id: hal-02797038 https://hal-univ-rennes1.archives-ouvertes.fr/hal-02797038}

Submitted on 15 Jun 2020

HAL is a multi-disciplinary open access archive for the deposit and dissemination of scientific research documents, whether they are published or not. The documents may come from teaching and research institutions in France or abroad, or from public or private research centers.
L'archive ouverte pluridisciplinaire HAL, est destinée au dépôt et à la diffusion de documents scientifiques de niveau recherche, publiés ou non, émanant des établissements d'enseignement et de recherche français ou étrangers, des laboratoires publics ou privés. 


\section{Complex epitaxy of tetragonal tungsten bronze K- Ta-Nb-O nanorods}

V. Demange ${ }^{1,2^{*}}$, Q. Simon ${ }^{3}$, F. Gouttefangeas ${ }^{2}$, L. Joanny ${ }^{2}$, M. Guilloux-Viry ${ }^{1,2}$

1 Univ Rennes, CNRS, ISCR -UMR 6226, F-35000 Rennes, France

2Univ Rennes, CNRS, ScanMAT-UMS 2001, F-35000 Rennes, France

${ }^{3}$ GREMAN, UMR 7347 CNRS - Université de Tours, F-37200 Tours, France

KEYWORDS. KTN; TTB; thin films;

ABSTRACT. Tetragonal tungsten bronze phases possess numerous important properties

(ferroelectricity, multiferroicity, piezoelectricity, optical non-linearity, electro-optics) that can be achieved by modifying their composition, in addition to their ability to grow as very anisotropic crystals. In this study, $\mathrm{K}_{5.06}\left(\mathrm{Ta}_{0.57} \mathrm{Nb}_{0.43}\right)_{10.99} \mathrm{O}_{30}$ tetragonal tungsten bronze phase thin films have been grown by pulsed laser deposition technique on (001) $\mathrm{SrTiO}_{3}$ 
and R-plane sapphire substrates. The films have grown according to two modes with respect to the substrate surface, i.e. as vertical nanorods with the [001] direction perpendicular to the substrate surface, and as horizontal nanorods with the [001] orientation parallel to the substrate surface and $<310>$ out-of-plane direction. Both vertical and horizontal nanorods present epitaxial relationships with the substrates. Careful study of epitaxial relationships showed a complex growth on both substrates that can be described in the framework of domain matching epitaxy resulting in several anti-phase domains formation for both kind of nanorods. These particular configurations are due to a high degree of coincidence between cations (anions) of the film with those of the substrate. This study shows the ability of ferroelectric TTB phases to grow as onedimensional objects with the possibility to tailor their polarization direction either normal to or parallel to the substrate surface.

\section{INTRODUCTION}

Piezoelectric materials produce an electrical signal in response to an applied force. Such materials are intensively used in numerous fields of the modern society (e.g. actuators, sensors, transducers for information, communications, industrial automation, medical diagnostics, energy 
harvesters from vibrations, etc.). Most devices use polycrystalline ceramics, in particular lead zirconate titanate $\mathrm{PbZr}_{1-\mathrm{x}} \mathrm{Ti}_{\mathrm{x}} \mathrm{O}_{3}(\mathrm{PZT})$ oxides that are up-to-date the most performant piezoelectric materials ${ }^{1}$. However, PZT materials contain a large amount of lead which is highly toxic. Governmental directives in Europe against hazardous substances have restricted the use of leadbased materials and oriented the research toward the exclusion or substitution of lead in electronic devices $^{2,3}$. Efforts on new lead-free materials have been mainly devoted to phases crystallizing in the perovskite structure, like $\mathrm{BaTiO}_{3}{ }^{4}$ and $(\mathrm{K}, \mathrm{Na}) \mathrm{NbO}_{3}(\mathrm{KNN})^{1,5}$. Even though they do not have the highest piezoelectric properties, lead-free materials can show a better efficiency with limitations of losses in the transfer of energy. State of the art materials may become competitive with lead-based materials but for limited devices and applications ${ }^{6}$. Therefore, research on new lead-free materials is still needed.

Beyond the intrinsic properties of a given composition, the shape of the piezoelectric material is also subject to intensive research with the development in recent past years of integrated piezoelectric nanogenerators, that are either based on piezoelectric thin films or on one dimensional (1D) nanostructures ${ }^{1,7}$. However, the piezoelectric performances of films or nanostructures are lower compared with that of single crystals. In most cases, lead-based and leadfree 1D nanostructures exhibit a polycrystalline and highly defective microstructure, that is deleterious for their intrinsic properties ${ }^{8}$. Therefore, a synthesis method of piezoelectric singlecrystalline nanostructures with controlled orientation (thus polarization direction), with very few process steps, is of great interest.

In this context, the tetragonal tungsten bronze (TTB) phases, that received little attention up to now compared to perovskite phases, are subject to increasing researches in reason of their numerous important properties (ferroelectricity, multiferroicity, piezoelectricity, optical non- 
linearity, electro-optics ${ }^{9-11}$ ) that can be achieved by modifying their composition, in addition to their ability to grow as very anisotropic crystals ${ }^{12-14}$. The crystallographic cell of most of the leadfree TTB niobates is strongly anisotropic (figure 1a,b) with $a_{\text {TTB }} \sim 12.5 \AA$, and $c_{\text {TTB }} \sim 4 \AA$ (space group (SG): $P 4 / m b m$ (paraelectric phase) or $P 4 b m$ (ferroelectric phase with the polarization direction along the [001] direction) $)^{15}$.

Their chemical formula is $\mathrm{A}_{2}{ }_{2}{ }_{2}{ }_{4} \mathrm{C}_{4} \mathrm{~B} 1_{2} \mathrm{~B} 2{ }_{8} \mathrm{O}_{30}$ where $\mathrm{A} 1, \mathrm{~A} 2, \mathrm{~B} 1, \mathrm{~B} 2$ and $\mathrm{C}$ (figure 1c) are crystallographic sites partially or fully occupied by cations located in squared (A1), pentagonal

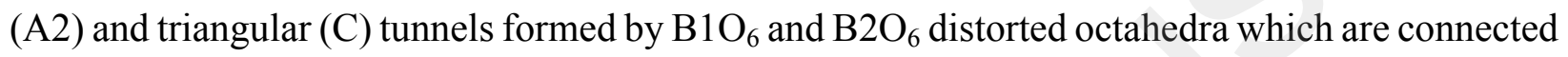
by apices. $\mathrm{A} 1$ and $\mathrm{A} 2$ sites are generally occupied by alkaline $\left(\mathrm{K}^{+}, \mathrm{Na}^{+}, \ldots\right)$ and alkaline earth $\left(\mathrm{Ca}^{2+}, \mathrm{Sr}^{2+}, \mathrm{Ba}^{2+}, \ldots\right)$ cations, whereas $\mathrm{B} 1$ and $\mathrm{B} 2$ sites are occupied by small and highly charged cations as $\mathrm{Nb}^{5+}$, which can be partially substituted by transition metals cations of different valences ${ }^{10}$. In most TTB compounds, the $\mathrm{C}$ sites are empty, but can be occupied by small cations ${ }^{16}$. When all the A1/A2 sites are fully occupied ("filled TTB"), the TTB crystals synthetized by solid state reaction methods usually grow as rods, the crystallographic anisotropy inducing a microstructural anisotropy. These rods can be as long as few millimetres, depending on the elements located in A1 and A2 sites ${ }^{12-14}$. In a previous work, we reported the growth of about 1 $\mu \mathrm{m}$ long $\mathrm{K}_{5.06}\left(\mathrm{Ta}_{0.57} \mathrm{Nb}_{0.43}\right)_{10.99} \mathrm{O}_{30}(\mathrm{KTN})$ TTB parallelepiped-shaped nanorods $\left(a_{\mathrm{TTB}}=12.537 \AA\right.$ $\pm 0.003 \AA, c_{\mathrm{TTB}}=3.975 \AA \pm 0.001 \AA$ ) on (1102) $\mathrm{Al}_{2} \mathrm{O}_{3}$ (R-plane sapphire) by pulsed laser deposition ${ }^{17}$. This niobate grows according to 2 modes with respect to the substrate surface: (i) as vertical nanorods with the [001] direction parallel to the surface substrate normal, and (ii) as horizontal nanorods with the [001] parallel to the substrate surface, as schematized in figure 2a.

As the physical properties of ferroelectric film depend on the polarization direction, therefore on the preferential orientation, it is mandatory to know the growth behaviour on 
single crystalline substrates. On the basis of this previous work, we studied here the structural growth relationships of KTN-TTB films on R-plane sapphire and on (001) $\mathrm{SrTiO}_{3}$ (STO) single crystal substrates, and showed that the films exhibit epitaxial relationships with both substrates. These two substrates are of great interest. Indeed, in spite of the difference of the structure of these two substrates, both can promote the epitaxial growth of TTB oxides, possibly with different state of strains. In addition, whereas $\mathrm{SrTiO}_{3}$ is a model substrate for the growth of many oxide thin films and suitable for many applications, in particular at low frequency, like piezoelectricity, sapphire is available in large dimensions and suitable for a large variety of applications including high frequency range thanks to its low dielectric permittivity and low dielectric losses. We describe the epitaxy relationships and discuss the results in relation with energetically preferential configurations.

\section{EXPERIMENTAL SECTION}

The pulsed laser deposition (PLD) target, of composition $\mathrm{KTa}_{0.65} \mathrm{Nb}_{0.35} \mathrm{O}_{3}+60$ mol. \% $\mathrm{KNO}_{3}$, was prepared by sintering a mixture of $\mathrm{KNbO}_{3}, \mathrm{KTaO}_{3}$ and $\mathrm{KNO}_{3}$ powders at $350^{\circ} \mathrm{C}$ 
for $12 \mathrm{~h}\left(\mathrm{KNO}_{3}\right.$ was used in order to introduce a potassium excess to counterbalance the depletion of potassium stoichiometry occurring during the deposition, due to the high volatility of potassium oxide $\mathrm{K}_{2} \mathrm{O}$ under high temperature $)^{18} \cdot \mathrm{KNbO}_{3}\left(\mathrm{KTaO}_{3}\right)$ compound was prepared by solid state reaction from $\mathrm{Nb}_{2} \mathrm{O}_{5}\left(\mathrm{Ta}_{2} \mathrm{O}_{5}\right)$ and $\mathrm{K}_{2} \mathrm{CO}_{3}, 1.5 \mathrm{H}_{2} \mathrm{O}$ precursors at $1000^{\circ} \mathrm{C}$ for $12 \mathrm{~h}$. The $\mathrm{KNO}_{3}, \mathrm{Ta}_{2} \mathrm{O}_{5}$ and $\mathrm{Nb}_{2} \mathrm{O}_{5}$ oxides were supplied by Alfa Aesar, and the $\mathrm{K}_{2} \mathrm{CO}_{3}, 1.5 \mathrm{H}_{2} \mathrm{O}$ hydrated potassium carbonate by Fluka. Prior to the deposition, the target was polished on dry 320 and 1200 grit SiC papers and cleaned by pulsed air.

The substrates were $5 \times 5 \mathrm{~mm}^{2}$ single crystalline $\mathrm{R}$-plane sapphire $\left(\mathrm{Al}_{2} \mathrm{O}_{3}(\overline{1} 102)\right.$, Joint Committee on Powder Diffraction Standards (JCPDS) card 00-010-0173, SG: $R \overline{3} C$ ( $\left.N^{\circ} 167\right), a=4.758 \AA, c=12.991 \AA$ ) and $5 \times 5 \mathrm{~mm}^{2}$ single crystal $(001) \mathrm{SrTiO}_{3}$ (labelled STO; JCPDS card 01-073-0661, SG: $P m \overline{3} m$ (N²21), $a=3.905 \AA$ Å), both supplied by Crystal $\mathrm{GmbH}$ Company. They were ultrasonically cleaned in acetone during $5 \mathrm{~min}$, then in isopropyl alcohol during $5 \mathrm{~min}$, prior to the deposition step.

$\mathrm{K}-\mathrm{Ta}-\mathrm{Nb}-\mathrm{O}$ (KTN) films were grown by PLD using a KrF excimer laser (Tuilaser Excistar, pulse duration of $20 \mathrm{~ns}, \lambda=248 \mathrm{~nm}$ ) operating at $2 \mathrm{~Hz}$ with an energy of $210 \mathrm{~mJ}$ (corresponding to a fluence of $2{\mathrm{~J} . \mathrm{cm}^{-2}}^{2}$. The target-substrate distance was fixed at 70 
$\mathrm{mm}$. During the deposition (30 min), the substrate temperature $\left(845^{\circ} \mathrm{C}\right.$ and $865^{\circ} \mathrm{C}$ ) and the oxygen pressure ( $30 \mathrm{~Pa}$ ) were kept constant. After deposition, samples were routinely cooled from deposition temperature down to room temperature within $30 \mathrm{~min}$, under an oxygen pressure of $2.6710^{4} \mathrm{~Pa}$. Scanning electron microscopy (SEM) was performed by using field emission gun Jeol JSM 6301F and Jeol JSM 7100 instruments working at 7 $\mathrm{kV}$ and at $5.0 \mathrm{kV}$, respectively. Chemical composition of the samples was characterized by energy dispersive X-ray spectroscopy (EDXS) by using a Jeol JSM 7100 instrument working at $10 \mathrm{kV}$ equipped with an Oxford Aztec EDS system. The samples were coated with carbon prior to the analysis. X-ray diffraction (XRD) in $\theta-2 \theta$ mode was carried out using a $\theta-2 \theta$ instrument (Bruker AXS D8 Advance) working with a monochromatized $\mathrm{Cu}$ Ka1 radiation and equipped with a 1D detector (192 channels). Data were collected across a $2 \theta$ range of $5-80^{\circ}$, using a $0.002^{\circ}$ step and acquisition time of $0.3 \mathrm{~s} / \mathrm{step}$. Phiscans and rocking curves were carried out using a 4-circle texture diffractometer (Bruker AXS D8 Discover) operating with a Cu Ka radiation equipped with a 1D detector (192 channels). Reciprocal space maps (RSM) of film grown on $\mathrm{SrTiO}_{3}$ (respectively on sapphire) were recorded on the same instrument equipped with a double Ge channel cut 
monochromator (respectively without monochromator); the maps were displayed thanks to the DxTools free software ${ }^{19}$.

\section{RESULTS AND DISCUSSION}

\subsection{Microstructure and preferential orientation}

Scanning electron micrographs of KTN-TTB films grown on (001)STO at $845^{\circ} \mathrm{C}$ and on R-plane sapphire at 845 and $865^{\circ} \mathrm{C}$ are displayed in figure 3 . Films are constituted of crystallites with two morphologies: i) elongated horizontal parallelepiped-shaped crystallites, distributed in two groups of variants growing at $90^{\circ}$ from each other, and ii) vertical parallelepiped-shaped nanorods. On STO, large areas of the substrate are mainly covered by horizontal crystallites, that are about $1 \mu \mathrm{m}$ long, $100 \mathrm{~nm}$ wide (fig. 3b) and 250 $\mathrm{nm}$ thick (fig. SI.1a). On the contrary, other areas are fully covered by vertical nanorods (fig. 3a), which are 50 to $100 \mathrm{~nm}$ wide, and 50 to $400 \mathrm{~nm}$ long (fig. $3 \mathrm{~b}$ ). For the film synthesized at $845^{\circ} \mathrm{C}$ on sapphire, the vertical rods have grown on the whole substrate (fig. 3c). Micrograph performed at a higher magnification on an edge of the samples shows also the presence of a layer made of horizontal elongated crystallites (fig. 3d). Film 
deposited at $865^{\circ} \mathrm{C}$ on sapphire presents also two kinds of areas, either covered by vertical rods or only by layer made of horizontal crystallites. On sapphire, vertical rods are of 50 to $100 \mathrm{~nm}$ wide and $1 \mu \mathrm{m}$ long (fig. $3 \mathrm{~d}$ and fig. SI. $1 \mathrm{~b}$ ). On both substrates, the vertical crystallites have grown between two adjacent horizontal crystallites.

The average compositions have been determined by EDXS on horizontal layer area and on vertical rods area (table 1). These measurements show that on a same substrate, the vertical and horizontal nanorods have similar values of measured composition. Samples grown on sapphire have the same measured composition, around $\mathrm{K}: 32 \%, \mathrm{Nb}$ : $23 \%$, Ta: $44 \%$ ( $\pm 3 \%)$ corresponding to a composition ratio around $\mathrm{K}_{5}\left(\mathrm{Ta}_{0.65} \mathrm{Nb}_{0.35}\right)_{10} \mathrm{O}_{\mathrm{x}}$, corresponding therefore to a partially filled TTB where 5 of the 6 A1 and A2 sites are occupied while measured composition of sample grown on STO indicates a higher amount of potassium and a slightly different metal ratio Ta/Nb, i.e. K: $38 \%, \mathrm{Nb}: 26 \%$, Ta: $35 \%( \pm 3 \%)$ corresponding to a composition ratio around $\mathrm{K}_{6}\left(\mathrm{Ta}_{0.6} \mathrm{Nb}_{0.4}\right)_{10} \mathrm{O}_{\mathrm{x}}$ and therefore to a filled TTB. The difference of composition can arise from to a difference in temperature leading at the substrate surface possibly to volatility of potassium and film/substrate diffusion effects as it has been previously observed for other systems ${ }^{20,21}$. 
Table 1. Average composition of KTN-TTB films analyzed by EDXS.

\begin{tabular}{|c|c|c|c|c|}
\hline \multirow[t]{2}{*}{ Samples } & \multicolumn{2}{|c|}{ Vertical rods area } & \multicolumn{2}{|c|}{ Horizontal rods area } \\
\hline & $\begin{array}{l}\text { Measured } \\
\text { composition }\end{array}$ & Composition ratio & $\begin{array}{l}\text { Measured } \\
\text { composition }\end{array}$ & Composition ratio \\
\hline $\begin{array}{l}\text { KTN- } \\
\text { (001)STO_845 } \\
\text { C }\end{array}$ & $\begin{array}{l}\mathrm{K}: 38.2 \pm 3 \% \\
\mathrm{Nb}: 26.8 \pm 3 \% \\
\mathrm{Ta}: 35 \pm 3 \%\end{array}$ & $\mathrm{~K}_{6.2}\left(\mathrm{Ta}_{0.57} \mathrm{Nb}_{0.43}\right)_{10}$ & $\begin{array}{l}\mathrm{K}: 37.5 \pm 3 \% \\
\mathrm{Nb}: 25.6 \pm 3 \% \\
\mathrm{Ta}: 36.9 \pm 3 \%\end{array}$ & $\mathrm{~K}_{6}\left(\mathrm{Ta}_{0.59} \mathrm{Nb}_{0.41}\right)_{10}$ \\
\hline $\begin{array}{l}\text { KTN-R- } \\
\text { sapphire_845 }{ }^{\circ} \mathrm{C}\end{array}$ & $\begin{array}{l}\mathrm{K}: 32.2 \pm 3 \% \\
\mathrm{Nb}: 23.5 \pm 3 \% \\
\text { Ta: } 44.3 \pm 3 \%\end{array}$ & $\mathrm{~K}_{4.8}\left(\mathrm{Ta}_{0.65} \mathrm{Nb}_{0.35}\right)_{10}$ & $\begin{array}{l}\mathrm{K}: 33.6 \pm 3 \% \\
\mathrm{Nb}: 22.5 \pm 3 \% \\
\mathrm{Ta}: 43.9 \pm 3 \%\end{array}$ & $\mathrm{~K}_{5}\left(\mathrm{Ta}_{0.66} \mathrm{Nb}_{0.34}\right)_{10}$ \\
\hline $\begin{array}{l}\text { KTN-R- } \\
\text { sapphire_865 } 8{ }^{\circ} \mathrm{C}\end{array}$ & $\begin{array}{l}\mathrm{K}: 30.9 \pm 3 \% \\
\mathrm{Nb}: 23.5 \pm 3 \% \\
\text { Ta: } 45.6 \pm 3 \%\end{array}$ & $\mathrm{~K}_{4.5}\left(\mathrm{Ta}_{0.66} \mathrm{Nb}_{0.34}\right)_{10}$ & $\begin{array}{l}\mathrm{K}: 31.6 \pm 3 \% \\
\mathrm{Nb}: 22.4 \pm 3 \% \\
\mathrm{Ta}: 46 \pm 3 \%\end{array}$ & $\mathrm{~K}_{4.3}\left(\mathrm{Ta}_{0.66} \mathrm{Nb}_{0.34}\right)_{1}$ \\
\hline
\end{tabular}

Figure 4 shows the $\theta / 2 \theta$ XRD patterns of the $\mathrm{KTN} /(001) \mathrm{STO}$ and $\mathrm{KTN} /$ sapphire films deposited at $845^{\circ} \mathrm{C}$. Pattern of the sample deposited on sapphire at $865^{\circ} \mathrm{C}$ is similar to 
that grown at $845^{\circ} \mathrm{C}$ (not shown). As seen in the figure $4 \mathrm{a}$, in addition to substrates reflections, only 001 and 310 TTB reflections are present for both films indicating that the TTB film was preferentially oriented along one or the other (or both) of these directions. Indeed, the lattice spacings $d_{001}$ and $d_{310}$ for a TTB structure are almost equal (for KTNTTB phase, $\mathrm{d}_{001}^{\mathrm{TTB}}=3.975 \AA$ and $\mathrm{d}_{310}^{\mathrm{TTB}}=a_{\mathrm{TTB}} / \sqrt{10}=3.964 \AA$ ).

Magnification of the XRD pattern around the 002 and 620 reflections shows that for the $\mathrm{KTN} /(001) \mathrm{STO}$ film this peak splits actually into two contributions with lattice spacings $d$ $=1.992 \pm 0.005 \AA$ and $1.987 \pm 0.005 \AA$ (fig. 4b). This splitting indicates that there are in fact two out-of-plane orientations in the film, namely [001] and $\langle 310\rangle$. No splitting is observed for the $\mathrm{KTN} /$ sapphire film deposited at $845^{\circ} \mathrm{C}$ neither for the one grown at $865^{\circ} \mathrm{C}$. This indicates that the lattice constants of the TTB are different on STO than on sapphire. This can be due either to a different strain state of the film as a function of the substrate or to the observed difference in composition (table 1). Indexation of these peaks gives the following lattice constants: $a_{\mathrm{TTB}}=12.570 \pm 0.005 \AA$; $c_{\mathrm{TTB}}=3.984 \pm 0.005 \AA$ on STO and $c_{\mathrm{TTB}}=3.975 \AA$ on R-plane sapphire (table 2). 
Table 2. Lattice constants of KTN-TTB phase determined by XRD in $\theta / 2 \theta$ mode and in asymmetric mode. The error value is $\pm 0.005 \AA$.

\begin{tabular}{|l|l|l|l|}
\hline \multirow{2}{*}{ Types of nanorods } & Measurement & $\begin{array}{l}\text { Lattice constants } \\
\text { on STO }\end{array}$ & Lattice constants \\
\hline \multirow{2}{*}{ Vertical nanorods } & Asymmetric & $a_{\mathrm{TTB}}^{\mathrm{Ver}}=12.550 \AA$ & $a_{\mathrm{TTB}}^{\mathrm{Ver}}=12.570 \AA$ \\
\cline { 2 - 4 } & Symmetric & $c_{\mathrm{TTB}}^{\mathrm{Ver}}=3.984 \AA$ & $c_{\mathrm{TTB}}^{\mathrm{Ver}}=3.975 \AA$ \\
\hline \multirow{2}{*}{$\begin{array}{l}\text { Horizontal } \\
\text { nanorods }\end{array}$} & Symmetric & $a_{\mathrm{TTB}}^{\mathrm{Hor}}=12.572 \AA$ & $a_{\mathrm{TTB}}^{\mathrm{Hor}}=12.567 \AA$ \\
\cline { 2 - 4 } & Symmetric & $c_{\mathrm{TTB}}^{\mathrm{Hor}}=3.967 \AA$ & $c_{\mathrm{TTB}}^{\mathrm{Hor}}=3.970 \AA$ \\
\hline
\end{tabular}

Rocking-curves of the 001 and 310 TTB reflections on both substrates are shown in figure SI.2a. The peak of the film grown on sapphire is wider (full width at half maximum $\left.\Delta \omega \sim 3^{\circ}\right)$ than the one of the film grown on STO $\left(\Delta \omega=0.9^{\circ}\right)$, indicating for the former a more important mosaicity, created by slight misorientations of different grown crystallites.

\subsection{Epitaxy study}


From previous transmission electron microscopy experiments, the growth direction of vertical nanorods was determined as being $[001]^{17}$ (see scheme of this orientation in figure $2 a$, left). Consequently, the crystallites grown with the out-of-plane <310> preferential orientation correspond to the in-plane elongated crystallites, as schematized in figure $2 a$ (center and right). To validate this assumption, phi-scans on vertical nanorods were performed on $\{311\}$ planes of the TTB phase, by orienting the sample at $2 \theta=31.72^{\circ}$ and $\chi \sim 45^{\circ}$ (calculated $45.11^{\circ}$ ), the latter angle corresponding to the angle between the (001) and $\{311\}$ planes. For the horizontal rods, phi-scans were performed on $\{210\}$ planes of TTB phase, by orienting the sample at $2 \theta=15.7^{\circ}$ and $\chi=45^{\circ}$, the angle between $\{310\}$ and $\{210\}$ planes being equal to $45^{\circ}$. Figure 5 shows the results on both substrates. For both substrates, intensities from horizontal nanorods ( $\{210\}$ phi-scan) are weaker than for vertical nanorods (\{311\} phi-scan). This difference in intensity is likely related to a difference of relative intensity between $311(I=999)$ and $210(I=379)$ reflections, according to the JCPDS card $\mathrm{n}^{\circ} 01-087-1856$ for the $\mathrm{K}_{6} \mathrm{Nb}_{10.88} \mathrm{O}_{30}$ compound. In addition, SEM micrographs in Fig. 3 suggest a higher number of vertical nanorods compared to horizontal nanorods than can partially explain the differences in intensities for phi-scans. 


\subsubsection{Epitaxy of (001)-oriented vertical nanorods}

On both substrates, phi-scans performed on $\{311\}$ planes shows 12 peaks, i.e. 4 peaks of the same intensity and located at $90^{\circ}$ from each other and 8 smaller peaks. The four most intense peaks are located at the same values of phi $(\phi)$ that the $\{110\}$ STO peaks, and at $\pm 45^{\circ}$ and $\pm 135^{\circ}$ of the (0006) sapphire peak. Each smaller peak is located at about $\pm 37^{\circ}$ from a larger peak position. On sapphire, the smaller peaks have an intensity half that of the largest peaks (Fig. 5a). On STO, it is not possible to determine the relative intensities of both kinds of peaks due to substrate contribution to the peaks located at about $0, \pm 90$ and $\pm 180^{\circ}$ (Fig. 5 b). Indeed, the reflection parameters for $\{110\} S T O$ planes are very close to that of the $\{311\}$ TTB planes, i.e. $2 \theta=32.42^{\circ}$ and $\chi=45^{\circ}$. Traces of $\{311\}$ planes in the (001) plane of the TTB phase are parallel to the $<310>$ directions. Therefore, the orientation relationships between the $<100>$ direction of the substrate (cubic $<100>$ for (001)STO, and pseudo-cubic $<100>$ for sapphire) and the $<310>$ directions of the TTB phase were determined from the phi-scans. 
Figure 6a shows one of the possible in-plane orientations, labelled $1 \mathrm{~A}$ in the figure. The tetragonal TTB unit cell is drawn in black lines and its in-plane ([100];[010]) orientation is defined by the black arrows. This unit cell is in-plane rotated of $18.43^{\circ}$ relatively to that of the substrate drawn in the middle of the figure 6. [150] and [310] directions of the TTB cell are then parallel to the [100] and [010] STO directions, respectively. With this particular orientation, it appears that the central square sub-unit defined by the potassium ions (red dashed lines) is parallel to the STO cell edges. By applying a mirror to this orientation perpendicularly to the [130] direction, the orientation $1 \mathrm{~B}$ is obtained (fig. $6 \mathrm{~b}$ ), which is equivalent and equiprobable to the previous one: the central square pattern is still parallel to the substrate cell. Thus, $1 \mathrm{~A}$ and $1 \mathrm{~B}$ orientations are at the origin of peaks in the phi-scans located at the same values of $\phi$ (Fig. 5a, 5b). The out-of-plane orientation of the variant $1 \mathrm{~A}$ is [001], while that of the variant $1 \mathrm{~B}$ is [001]. Orientations $1 \mathrm{~A}$ and $1 \mathrm{~B}$ are anti-phase domains. By applying to the crystal 1A, an in-plane clockwise rotation of $\phi=$ $53.13^{\circ}$, the orientation displayed in figure $6 \mathrm{c}$ is obtained, which corresponds in the phiscan to a peak located at $\Delta \phi=+53.13^{\circ}$ from the variant $1 \mathrm{~A}$ peak. With this orientation, the $[\overline{3} 10]$ and [130] directions are then parallel to the [100] and [010] STO directions, and 
in this case, the square pattern located at the vertices of the cell (green dashed lines) is now parallel to the edges of the substrate cell. This orientation is also equiprobable to the orientations $1 \mathrm{~A}$ and $1 \mathrm{~B}$.

Actually, this orientation is identical to $1 \mathrm{~B}$. By shifting the unit cell origin of $1 / 2 a+1 / 2 b$ (shift of the black unit cell to the yellow cell in figure 6c), the cell drawn in figure $6 b$ is recovered. By applying to these orientation a mirror perpendicular to the $[\overline{3} 10]$ direction, another anti-phase domain is obtained (figure $6 \mathrm{~d}$ ), identical of the orientation $1 \mathrm{~A}$. This last orientation can also be obtained by rotating the crystal $1 \mathrm{~B}$ by $\phi=36.87^{\circ}$ clockwise and corresponds in the phi-scan to a peak located at $\Delta \phi=+36.87^{\circ}$ from the variant 1B peak.

Figure 7 shows the corresponding positions in the phi-scans of supplementary rotations of $\phi=36.87^{\circ}$ and $53.13^{\circ}$ applied on the variants $1 \mathrm{~A}$ and $1 \mathrm{~B}$. The most intense peak correspond to the presence of both orientations at the same phi-value, every $90^{\circ}$. Rotation of $1 \mathrm{~A}$ by $53.13^{\circ}$ leads to $1 \mathrm{~B}$ alone while rotation of $1 \mathrm{~B}$ by $36.87^{\circ}$ leads to $1 \mathrm{~A}$ alone. Therefore the intensity of the peaks located at these values (relatively to the strongest 
peaks) are half that of the strongest peak. This conclusion is validated by simulating the $\{311\}$ pole figures for each orientation.

Figure 8 presents the simulated pole figure of orientation $1 \mathrm{~A}$, superposed to that of domain 1B (i.e. superposition of domains oriented along [001]); twelve poles are then observed: four at $\phi=90^{\circ}$ from each other, and for which the intensity is twice that of the eight other peaks located at $\phi=+36.87^{\circ}$ and $\phi=+57.13^{\circ}$ relatively to the four former peaks. This result agrees with the experimental pole figure displayed in figure $8 \mathrm{~b}$. Figure $2 b$ is a schematic representation of these two variants, corresponding to vertical nanorods oriented on the STO substrate (left panel of the figure). Figure $6 e$ is the superposition of the variant $1 \mathrm{~A}$ with the STO lattice showing the coincidence between the unit cell constant $a_{\text {TTB }}$ of the TTB cell and the diagonal of $3 \times 1$ unit cells of the substrate. Coincidence between the 2 lattices corresponds to $a_{\mathrm{TTB}}{ }^{2} \approx a_{\mathrm{STO}}{ }^{2}+\left(3 a_{\mathrm{STO}}\right)^{2}$, which leads to $a_{\mathrm{TTB}}=\sqrt{10}$ $\mathrm{d}_{310}^{\mathrm{TTB}} \approx \sqrt{10} a_{\text {STO}}$. The in-plane rotation between the two cells is then equal to $\arctan \left(a_{\mathrm{STO}} / 3 a_{\mathrm{STO}}\right)=\arctan (1 / 3)=18.43^{\circ}$. Therefore, each anti-phase domain corresponds to a disorientation of the TTB cell of $\pm 18.4^{\circ}$ relatively to the substrate cell. The epitaxy is due to the small lateral mismatch value determined by the following 


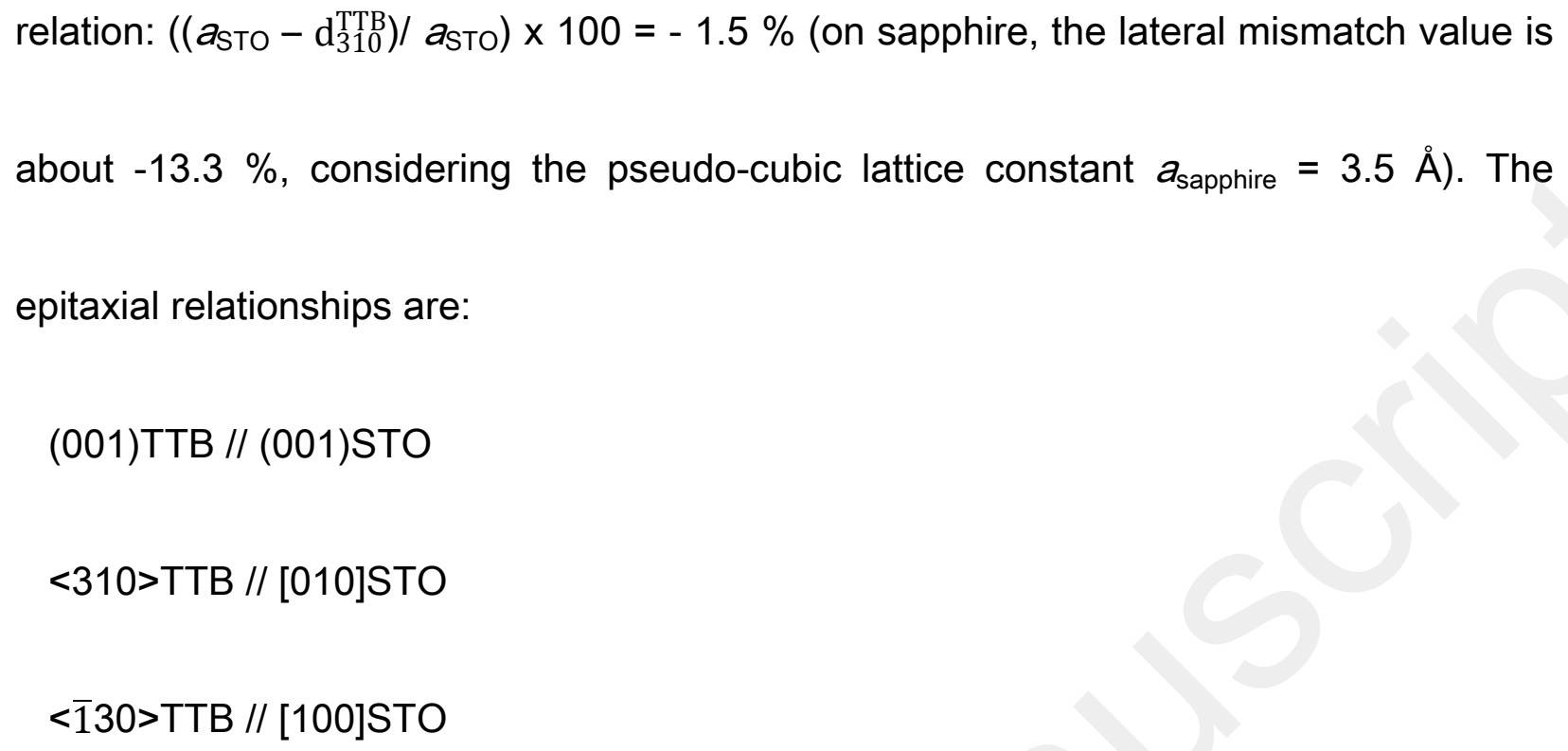

Figure $6 \mathrm{f}$ is the picture of domain $1 \mathrm{~A}$ in cross-sectional view (the two variants are equivalent), showing that the interface between the crystallites and the substrate is expected to be flat. The rocking curves of the $\{311\}$ orientations, were measured on both substrates (figure SI.3b). Film mosaicity is of $\Delta \omega \sim 3^{\circ}$ on sapphire and $\Delta \omega \sim 0.4^{\circ}$ on STO, respectively which indicates again a more important disorientation of the nanorods on sapphire with respect to their growth direction, than on STO.

\subsubsection{Epitaxy of (310)-oriented nanorods}


Phi-scans performed on $\{210\}$ planes of the TTB on both substrates are shown in figure

5. One can observe $90^{\circ}$-spaced four peaks of same intensity, at the same azimuths that the ones of $\{110\} S T O$, and at $\pm 45^{\circ}$ and $\pm 135^{\circ}$ of the (0006)sapphire peak, respectively.

This result confirms that the in-plane elongated crystallites observed by SEM are out-ofplane oriented along the $\langle 310\rangle$ directions. The peaks at 0 and $180^{\circ}$ correspond to the variants labelled $2 A$ and $2 B$ in figure $2 b$, and the 2 other peaks are related to the variants (labelled 3A and 3B, fig. 2b) which is in-plane rotated by $90^{\circ}$ relatively to the former one. Intersections of $\{210\}$ planes with the (001) plane of the TTB phase are parallel to the $<310>$ directions. Therefore, the orientation relationships between the in-plane [001] direction of the TTB phase and the in-plane $<001>$ cubic (or pseudo-cubic) directions of the substrate can be determined from the phi-scans. Figure 9 is the corresponding scheme of the interface in cross-sectional view between the horizontal nanorods and the substrate. Similar results are obtained by considering the pseudo-cubic cell of the sapphire (cf. figure SI.3), except that the TTB cell is slightly disoriented of about $4^{\circ}$ due to the angle between $(\overline{1} 102)$ and $(0 \overline{1} \overline{2})$ planes of sapphire $\left(94^{\circ}\right)$. This result is fully in agreement with the high resolution transmission electron microscopy (HRTEM) 
micrographs published by Jia et $a .^{22}$ on a $\mathrm{Ca}_{0.28} \mathrm{Ba}_{0.72} \mathrm{Nb}_{2} \mathrm{O}_{6}(\mathrm{CBN})$ thin film grown on (001)STO by PLD. Figure 9 shows the two variants 2A (fig. 9a) and 3A (fig. 9b); both have the same out-of-plane growth direction, namely [130], but are in-plane rotated from each other by $90^{\circ}$, the growth direction being the rotation axis.

These two variants are equivalent and equiprobable. The [001] and [ $\overline{3} 10]$ directions of variant $2 \mathrm{~A}$ are parallel to the $a$ and $b$ substrate directions, and similarly, the [310] and [001] directions of variant $3 A$ are parallel to the $a$ and $b$ substrate directions. By applying a vertical mirror perpendicular to each direction, two other equivalent variants, $2 \mathrm{~B}$ and $3 \mathrm{~B}$, are obtained as schematized in figure $2 \mathrm{~b}$. These variants are also anti-phase domains. One can observe here also that the square patterns located at the cell vertices (drawn with dashed lines in figure 9a) are parallel to the cubic cell of the substrate. As shown in fig. 9a, the orientation of both cells relatively to each other and their respective complex crystalline structures lead to a rough interface based on a substrate surface made of half-cell steps and terraces, as pointed out in the work of Jia et al. ${ }^{22}$ Figure 10 presents these two same variants in plane-view, showing that the lattice constant $c$ of the TTB phase is systematically parallel to one of the substrate lattice constants. Pole figures 
for these orientations were computed (fig. 10c and d) and superposed (fig. 10e): the obtained figure presents four poles oriented at $90^{\circ}$ from each other, in agreement with the $\{210\}$ phi-scan in the figure 5 . The epitaxial relationships are:

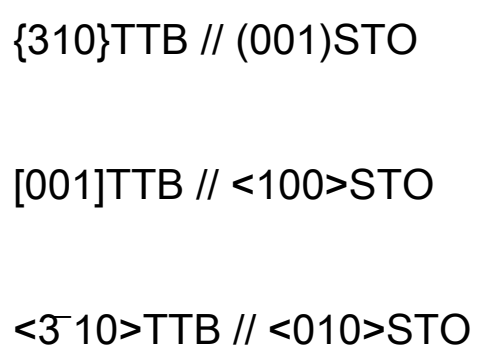

In the elongation direction, the lateral mismatch is equal to $\left(\left(a_{\text {STO }}-c_{\text {TTB }}\right) / a_{\text {STO }}\right) \times 100=$ $-1.79 \%$; in the other in-plane direction the mismatch is equal to $\left(\left(a_{\mathrm{STO}}-\mathrm{d}_{310}^{\mathrm{TTB}}\right) / a_{\mathrm{STO}}\right) \mathrm{x}$ $100=-1.5 \%$. Although the above determined mismatches are small, there is no obvious lattice coincidence between the TTB and substrate cells across the interface, as schematized in fig. 9a. For sapphire, these two values are about -13.6 and $-13.3 \%$, respectively. The rocking curves of the 210 reflections were measured on both substrates (figure SI.3c). Film mosaicity is $\Delta \omega \sim 3.5^{\circ}$ on sapphire and $\Delta \omega \sim 0.6^{\circ}$ on STO, respectively, enlightening again that crystallites on sapphire present larger disorientation relatively to the substrate than on STO. 


\subsubsection{Lattice constants}

Although the KTN-TTB phase grows with epitaxial relationships on both substrates, the important difference between the relative mismatch values indicates that the film on STO is expected to be more strained than the film on sapphire. In order to confirm this point, the out-of-plane and in-plane lattice constants of the two kinds of nanorods (i.e. horizontally and vertically grown) were measured on both substrates. In addition to the out-of-plane lattice constants determined by symmetric $\theta / 2 \theta$ experiments (figure 4 , table 2), asymmetric $\theta / 2 \theta$ scans and RSMs were recorded to measure the in-plane lattice constants of the phase, and compared with schemes of the reciprocal space for each variant. Figure 11 shows the symmetric (002)STO (fig. 11a), and asymmetric (103)STO (fig. 11b) and (133)STO (fig. 11c) maps. In the (002)STO map, the (002) ver (variant 1A) and $(620)_{\text {Hor }}(2 A, 3 A)$ reflections of the TTB phase are observed in agreement with the $\theta / 2 \theta$ scan displayed in figure 4 and to the scheme of the reciprocal space shown in the right part of the figure (in addition, several asymmetric maps are schematized in the figure $11 \mathrm{~b}$ in which the reflections that appear in the (002) map (figure 11a) are encircled in 
blue). In the experimental (103)STO map (left map in figure 11b), the reflections due to the TTB phase are observed below that of the substrate. A second map focused on these film reflections was recorded in a mode that allows better signal to noise ratio conditions (right map in the figure). The reflections that appear in the (103) map, namely $(3 \overline{1} 3)_{\text {Ver }}$ (variant $1 \mathrm{~A}),(680)_{\text {Hor }}(2 \mathrm{~A})$ and $(\overline{3} 9 \overline{1})_{\text {Hor }}(3 \mathrm{~A})$ are encircled in red in schemes of the reciprocal space areas in figure $11 \mathrm{~b}$, and resulting superposition is displayed in the right panel of this figure. This scheme shows that $(3 \overline{1} 3)_{\text {Ver }}$ and $(\overline{3} 9 \overline{1})_{\text {Hor }}$ reflections are superposed while the $(680)_{\text {Hor }}$ reflection is located just below the two previous ones. Therefore, it is not possible to distinguish unambiguously the reflections due to the vertical $1 \mathrm{~A}$ and horizontal $3 \mathrm{~A}$ crystals, consequently the measurement of the lattice constant of vertical crystal is not possible. Therefore, a third map was recorded by considering the orientation described in figure 6e, and obtained after an in-plane rotation $\phi$ of the sample of $18.4^{\circ}$ relatively to the angular position corresponding to the (103)STO map. In this case, the (133)STO map is obtained and only the vertical crystallites are able to diffract. Figure 11c shows this experimental (133)STO map, where both expected reflections (film and substrate) are observed, together with a second map focused on the film reflection, 
indexed as being (0 $\overline{103})$ TTB reflection, as depicted in the scheme of the reciprocal space displayed in fig. 11c. From this result, the corresponding in-plane lattice constant is equal to $a_{\mathrm{TTB}}^{\mathrm{Ver}}=12.55 \AA$.

Concerning the horizontal crystallites, the lattice constant $c_{\mathrm{TTB}}^{\text {Hor }}$ is equal to $3.967 \AA$ from an asymmetric (210)STO scan that shows both reflections (621) $)_{\text {Hor }}$ and (312) Ver (figure

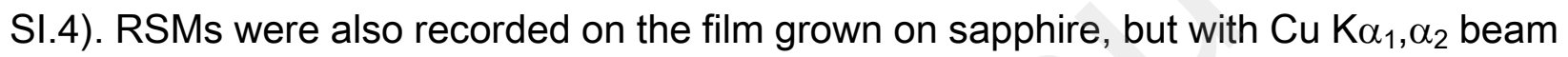
(figure SI.5). Indeed, with the use of the monochromator, the film reflection intensity was too weak to be detected, due to the small thickness and/or the mosaicity impact. One can observe in the symmetric map of KTN/sapphire (figure SI.5a) that the (002) Ver film reflection is not vertically aligned with the substrate reflection. This misorientation (about $4^{\circ}$ ) is due to the pseudo-cubic cell of sapphire that forms an angle of $94^{\circ}$ instead of $90^{\circ}$ and induces an inclination of the above film cell ( $c f$. scheme in figure SI.3).

All the determined lattice constants on both substrates are listed in table 2. On sapphire, the lattice constants $a_{\text {TTB }}$ and $c_{\text {TTB }}$ are approximately the same for both horizontal and vertical nanorods. On STO on the contrary, the $c_{\text {TTB }}$ lattice constant is slightly lower for the horizontal rods, than for the vertical rods, and accordingly the वाтв $_{\text {Tि }}$ is higher for the 
horizontal rods than for the vertical rods indicating an in-plane compressive state of both kinds of rods. These results are in agreement with the small mismatch values determined for film grown on STO, while the films grown on sapphire are fully relaxed in reason of the large mismatch values. This also explains the greater crystallites disorientation on sapphire leading to the broadening of the rocking-curve.

\subsection{Horizontal versus vertical nanorods}

Since the determined lattice constants are rather similar for both kind of crystallites (vertical $v s$ horizontal rods) whatever the substrate is, and since both kind of crystallites are growing on both substrates, it appears that the epitaxial mismatch is not at the origin of the growth of one kind of rods rather the second one. Infortuna et al. have demonstrated the influence of the last atomic plane of the STO substrate on the growth of $\mathrm{Sr}_{x} \mathrm{Ba}_{1-\mathrm{x}} \mathrm{Nb}_{2} \mathrm{O}_{6}$ (SBN) TTB phase ${ }^{23}$ : if the substrate is terminated by a SrO plane, growth of a (001)oriented columnar film is observed, while for $\mathrm{TiO}_{2}$-terminated plane, $\{310\}$-oriented rods are observed. Inversely, Jia et al. ${ }^{22}$ have shown that the growth of (001)-oriented domain of $\mathrm{CBN}$, TTB is preferential on $\mathrm{TiO}_{2}$-termination in reason of a better atomic matching in 
this configuration than on SrO-plane. Although these results look antagonist at the first sight, they deal with two different compounds, that were moreover deposited at very different partial oxygen pressures (between 200-400 mTorr for the former and at 1.5 mTorr for the latter) and at different deposition temperatures (between $730-760^{\circ} \mathrm{C}$ for the former and between 600 and $800^{\circ} \mathrm{C}$ for the latter). Indeed, Ebina et al. have shown that for SBN $(x=0.5)$ films grown on $(\mathrm{La}, \mathrm{Sr}) \mathrm{TiO}_{3}$ substrate, the preferential orientations depend both on the oxygen partial pressure and on the deposition temperature ${ }^{24}$. We have made preliminary experiments showing that the surface termination of the STO substrate is a key parameter for the growth of KTN TTB nanorods either vertically or horizontally. $\mathrm{TiO}_{2}$-terminated surface involves the growth of horizontal rods only (these results are not shown here, and will be the subject of another article). The TTB phases often show an anisotropic growth with the $\mathrm{c}$ axis being the elongation direction. This particular growth has been observed for materials obtained as powder, anisotropy of particles being reinforced by different synthesis processes ${ }^{12,25-27}$. Concerning thin films of TTB phases, growth of epitaxial layer according a Volmer-Weber mode was reported by only 3 groups, with either growth of horizontal rods by sol-gel method ${ }^{28,29}$, and by PLD 
after chemical treatment of the surface ${ }^{23}$, or columnar growth by $\operatorname{PLD}^{23,30}$. As far we known, our study is the only one dealing with vertical nanorods perfectly isolated from each other.

\subsection{Anti-phase domains}

Previous studies on (001)SBN and CBN TTB thin films grown on (001)STO, (001) $\mathrm{LaNiO}_{3} / \mathrm{CeO}_{2} / \mathrm{YSZ} / \mathrm{Si}$ and $(001) \mathrm{MgO}$ substrates have shown that films form in-plane antiphase domains as observed in the present study $20,21,28-35$. On MgO in particular, 3 kinds of domains have been determined, whatever the synthesis method is, with $0^{\circ}, \pm$ $18.43^{\circ}(=\arctan (1 / 3))$, et $\pm 30.96^{\circ}(=\arctan (3 / 5))$ in-plane orientations (sometimes simultaneously) relatively to the main directions of the substrate. Growth on $\mathrm{MgO}$ of domains turned by $\pm 18.43^{\circ}$ is considered as a minimal electrostatic energy configuration ${ }^{31}$. Willmott et al. have shown that the proportion of each domain $\left(0^{\circ}, \pm\right.$ $18.43^{\circ}, \pm 30.96^{\circ}$ ) in a same film of SBN was a function of the amount $x$, with a predominance $(\sim 90 \%)$ for domains at $\pm 18.43^{\circ}$ for $x \geq 0.55^{36}$, although this is the configuration for which the mismatch is the most important. On the contrary, on STO, only 


\begin{abstract}
the domains oriented at $\pm 18.43^{\circ}$ in the plane have been observed (with mismatch values of $0.83 \%$ and $1.58 \%$ for $\mathrm{CBN})^{22,23}$, in agreement with our results. No results on sapphire have been reported so far.
\end{abstract}

The factors that control the epitaxial growth are the misfit along the interface, the density of coincident atom sites at the interface and the nature of the chemical interaction at the interface 38,39 . In case of usual $(001) \mathrm{ABO}_{3}$ perovskite growth on $(001) \mathrm{A}^{\prime} \mathrm{B}^{\prime} \mathrm{O}_{3}$ perovskite substrate (for instance, $\mathrm{KNbO}_{3}$ on $\mathrm{SrTiO}_{3}$ which is a system chemically close to the present one), the epitaxy is characterized by a cube-on-cube growth and an alignment of the perovskite subunits (PSU) of the substrate with those of the film at the interface. This results in the following sequence of layers at the interface: $\mathrm{BO}_{2} / \mathrm{AO} / \mathrm{BO}_{2} / \mathrm{A}^{\prime} \mathrm{O} / \mathrm{B}^{\prime} \mathrm{O}_{2}$ or $\mathrm{BO}_{2} / \mathrm{AO} / \mathrm{B}^{\prime} \mathrm{O}_{2} / \mathrm{A}^{\prime} \mathrm{O}$ (for instance $\mathrm{TiO}_{2} / \mathrm{SrO} / \mathrm{TiO}_{2} / \mathrm{KO} / \mathrm{NbO}_{2}$ or $\mathrm{TiO}_{2} / \mathrm{SrO} / \mathrm{NbO}_{2} / \mathrm{KO}$ ).

Regarding the epitaxial growth of the KTN TTB phase on STO, three different epitaxy configurations can be examined: i) a cube-on-cube growth with the tetragonal TTB cell parallel to the STO cell, corresponding to the growth on one cell of TTB on nine cells of STO, ii) a TTB PSU growth on STO PSU, iii) a domain matching epitaxy (DME, see below). We have calculated the mismatch of these 3 configurations (cf. table 3 ). 
Table 3. Mismatch values between TTB cell and STO cell for the three different epitaxy configurations.

\begin{tabular}{|l|l|l|l|}
\hline $\begin{array}{l}\text { Out-of-plane } \\
\text { orientation }\end{array}$ & $\begin{array}{l}\text { Cube-on-cube } \\
\text { mismatch }\end{array}$ & $\begin{array}{l}\text { TTB PSU on STO } \\
\text { PSU mismatch }\end{array}$ & DME mismatch \\
\hline$(001)$ & $-7.01 \%$ & $-0.38 \%$ & $-1.52 \%$ \\
\hline$(130)$ & $-7.01 \%$ & $-0.38 \%$ & $-1.52 \%$ \\
& $-1.79 \%$ & $-1.79 \%$ & $-1.79 \%$ \\
\hline
\end{tabular}

If the lattices were superposed cube-on-cube (i.e. one cell of TTB on nine cells of STO), the mismatch will be equal to $\Delta a l a=\left(3 a_{\text {STO- }}-a_{\text {TRB }}\right) / 3 a_{\text {STO }}=-7 \%(12.2$ and $-19.4 \%$ in the case of sapphire). In the case of SBN grown on (001)MgO, the mismatch would be equal to $-1.1 \%$ if the film follows such configuration whereas it is equal to $-6.2 \%$ for the experimental growth actually observed with in-plane domains at $\pm 18.43^{\circ 32}$. Therefore, it may be surprising to observe such growth if only the lattice coincidence is considered, but cube-on-cube growth will actually result in a charges conflict at several lattice 
positions. Jia et al. have simulated the cube-on-cube configuration for CBN TTB on STO and shown that there were no coincidence between both lattices ${ }^{22}$.

It could be expected that the perovskite sub-units of the TTB cell are aligned on the perovskite cell substrate (which is actually not what it is observed here). The TTB PSU have for dimensions $3.92 \AA$ in the $(a, b)$ plane and $3.975 \AA$ along $c$, which would correspond to mismatch values of $\Delta a / a=\left(a_{\text {STO }}-a_{\text {TTB-PSU }}\right) / a_{\text {STO }}=-0.38 \%$ for the vertical nanorods, and $-0.38 \%$ and $-1.79 \%$ for the horizontal nanorods if a TTB PSU was grown on a STO PSU. These mismatch values are very small. We have simulated this configuration, i.e. (001) TTB PSU on (001)STO PSU for cations and oxygen ions of both structures (fig. 12a and 12b). It is observed that this configuration presents actually a poor degree of coincidence between cations and anions of both structures. As seen above, the experimental results have shown that the actual configuration for the (001) texture, is the coincidence of the lattice constant $a_{\text {TTB }}$ of the TTB cell with the diagonal of $3 \times 1$ unit cells of the substrate (Figure 6e), indicating that the growth is governed by other phenomena. The complex epitaxy observed here can be described in the framework of the domain matching epitaxy (DME), in which the epitaxial growth is governed by domain orientation 
relationships where $m$ lattice units of the film match with $p$ lattice units of the substrate, with in our case an in-plane rotation of the epilayer relative to that of the substrate ${ }^{39,40}$. Zheleva et al. have shown that the DME takes place because this configuration is energetically favourable compared to the lattice epitaxial growth ${ }^{38}$.

Jia et al. have shown that the epitaxy of CBN on STO in the form of domains oriented at $18.43^{\circ}$ corresponds to a high degree of coincidence between the cations of the TTB phase and that of the substrate, and that is the same for oxygen anions of the two structures ${ }^{22}$. In particular, there is a coincidence of the cations located on the A1 sites of the TTB phase with the Sr ions of STO, and a good match between the A2 cations with the Sr ions. Regarding the B1 and B2 cations, there is coincidence with the Ti cations of the substrate for $20 \%$ of them, a good match for other $20 \%$, and no match for the remaining $40 \%$. Finally, for the $<310>$-oriented domains, the faceting allows the interface planes to avoid the areas of the structure where there is a bad lattice fit. Similarly to CBN on STO, we have simulated the growth of (001) (fig. 12c,d) and (310) (figure SI.6) KTN TTB phase in plane-view with respect of cations and anions positions relatively to those of the substrate. Actually, if we observe also a coincidence between A1 of (001) TTB with 
the cations of (001)STO, the matching between the B1/B2 sites of TTB with the Ti cations of STO is less good for KTN than for CBN (fig. 12c), and the coincidence sites of oxygen ions (fig. 12d) are less numerous than for the cations lattices. Mismatches between CBN and STO are equal to $-0.83 \%$ and $1.58 \%$, whereas our results for KTN on STO leads to values of $-1.52 \%$ and $-1.79 \%$. Concerning the (310) growth, the coincidence between elements of the film and those of the substrate in plane-view is clearly evidenced in the figure SI.6. In addition, if there is no obvious coincidence in cross-sectional view between film and substrate (fig. 9a), one can observe a lattice coincidence between the TTB phase and the substrate along the orange solid lines drawn in the figure 9a, corresponding to the (210) ттв planes, on which the cations of both structures are perfectly aligned, at least in the first cell layer of the film. These lines are aligned along the $<011>$ STO direction, thus tilted by $45^{\circ}$ relatively to the substrate surface. Therefore, we observed here, instead of the usual matching between the out-of-plane edges of the substrates cell and those of the epilayer, a 'tilted epitaxy' with the following matching $\mathrm{d}_{001}^{\mathrm{STO}}(=11.04 \AA) \sim 2 \mathrm{~d}_{210}^{\mathrm{TTB}}(=11.24$ Å). 


\section{CONCLUSION}

In conclusion, we have reported the growth of epitaxial KTN tetragonal bronze films by pulsed laser deposition. Characterization by scanning electron microscopy showed films made of horizontal and vertical nanorods. X-ray diffraction analyses evidenced that the horizontal rods have a $<310>$ out-of-plane preferential orientation while the vertical nanorods have a [001] preferential orientation. In both cases, the nanorods exhibit complex epitaxy relationships with the two studied substrates, i.e. (001) $\mathrm{SrTiO}_{3}$ and Rplane sapphire. For the [001] growth, antiphase domains rotated in-plane by $\pm 18.43^{\circ}$ with respect to the $<100>$ direction of the cubic (or pseudo-cubic for sapphire) of the substrate were observed. For the [310] growth, antiphase domains are also observed, and they are also rotated out-of-plane by $\pm 18.43^{\circ}$ with respect to the out-of-plane direction of the substrates. The [001] is then parallel to the substrate surface. The different possible configurations result in 6 variants on the same substrate. Among different models, this complex epitaxy is best described in the framework of the domain matching epitaxy, for which the degree of coincidence between cations (anions) of the film and those of the substrate is much higher than other possible epitaxy configurations. Since the polarization 
direction of ferroelectric TTB phases are along the [001] direction, it is observed here the possibility to tailor this direction with the deposition temperature or the substrate surface preparation. Indeed, the ability of this phase to grow as vertical isolated nanorods opens interesting perspectives as potential materials for integrated piezoelectric nanogenerators or nanotransducers for stimulation in nanomedicine.

\section{ASSOCIATED CONTENT}

Supporting Information. The following files are available free of charge. Cross-sectional SEM; Rocking-curves; Scheme of interface between TTB and sapphire; Asymmetric XRD

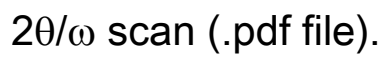

\section{AUTHOR INFORMATION \\ Corresponding Author \\ * valerie.demange@univ-rennes1.fr}

\section{Author Contributions}

The manuscript was written through contributions of all authors. All authors have given approval to the final version of the manuscript. 


\title{
Funding Sources
}

ISCR and ScanMAT received a financial support from the Région Bretagne, Rennes Métropole, the Département d'Ille et Vilaine and the European Union (CPER-FEDER 2007-2014, Présage Nos. 39126 and 37339, and CPER 2015-2020 MULTIMAT ScanMAT).

\section{ACKNOWLEDGEMENTS}

Scanning Electron Microscopy was performed on ScanMAT facilities platforms (UMS

2001, University of Rennes 1-CNRS). Dr André Perrin is warmly acknowledged for fruitful

discussions.

\begin{abstract}
ABBREVIATIONS
$\mathrm{CBN}, \mathrm{Ca}_{0.28} \mathrm{Ba}_{0.72} \mathrm{Nb}_{2} \mathrm{O}_{6}$; DME, domain matching epitaxy; EDXS, energy dispersive X-ray spectroscopy; HRTEM, high resolution transmission electron microscopy; JCPDS, Joint Committee on Powder Diffraction Standards; KNN, $(\mathrm{K}, \mathrm{Na}) \mathrm{NbO}_{3} ; \quad \mathrm{KTN}$, $\mathrm{K}_{5.06}\left(\mathrm{Ta}_{0.57} \mathrm{Nb}_{0.43}\right)_{10.99} \mathrm{O}_{30}$; PLD, pulsed laser deposition; PSU, perovskite subunits; PZT, $\mathrm{PbZr}_{1-}$ ${ }_{\mathrm{x}} \mathrm{Ti}_{\mathrm{x}} \mathrm{O}_{3}$; RSM, Reciprocal space maps; $\mathrm{SBN}, \mathrm{Sr}_{\mathrm{x}} \mathrm{Ba}_{1-\mathrm{x}} \mathrm{Nb}_{2} \mathrm{O}_{6}$; SEM, Scanning electron microscopy; STO, $\mathrm{SrTiO}_{3}$; TTB, Tetragonal tungsten bronze phases; XRD, X-ray diffraction.
\end{abstract}

\section{REFERENCES}

(1) Bowen, C. R.; Kim, H. A.; Weaver, P. M.; Dunn, S. Piezoelectric and Ferroelectric Materials and Structures for Energy Harvesting Applications. Energy Environ. Sci. 2014, 7, 25-44. https://doi.org/10.1039/c3ee42454e.

(2) European Parliament, Council of the European Union. EU-Directive 2002/95/EC. Restriction of the Use of Certain Hazardous Substances in Electrical and Electronic Equipment (RoHS). 2003, pp 1923.

(3) European Parliament, Council of the European Union. EU-Directive 2002/96/EC, "Waste Electrical and Electronic Equipment (WEEE). 2003, pp 24-38. 
(4) Jaffe, H. Piezoelectric Ceramics. J. Am. Ceram. Soc. 1958, 41, 494-498. https://doi.org/10.1111/j.1151-2916.1958.tb12903.x.

(5) Li, J.-F.; Wang, K.; Zhu, F.-Y.; Cheng, L.-Q.; Yao, F.-Z. (K, Na) $\mathrm{NbO}_{3}$-Based Lead-Free Piezoceramics: Fundamental Aspects, Processing Technologies, and Remaining Challenges. J. Am. Ceram. Soc. 2013, 96, 3677-3696. https://doi.org/10.1111/jace.12715.

(6) Rödel, J.; Webber, K. G.; Dittmer, R.; Jo, W.; Kimura, M.; Damjanovic, D. Transferring Lead-Free Piezoelectric Ceramics into Application. J. Eur. Ceram. Soc. 2015, 35, 1659-1681. https://doi.org/10.1016/j.jeurceramsoc.2014.12.013.

(7) Kumar, B.; Kim, S.-W. Recent Advances in Power Generation through Piezoelectric Nanogenerators. J. Mater. Chem. 2011, 21, 18946-18958. https://doi.org/10.1039/c1jm13066h.

(8) Jung, J. H.; Lee, M.; Hong, J.-I.; Ding, Y.; Chen, C.-Y.; Chou, L.-J.; Wang, Z. L. Lead-Free $\mathrm{NaNbO}_{3}$ Nanowires for a High Output Piezoelectric Nanogenerator. ACS Nano 2011, 5, 10041-10046. https://doi.org/10.1021/nn2039033.

(9) Neurgaonkar, R. R.; Oliver, J. R.; Cory, W. K.; Cross, L. E.; Viehland, D. Piezoelectricity in Tungsten Bronze Crystals. Ferroelectrics 1994, 160, 265-276. https://doi.org/10.1080/00150199408222463.

(10) Simon, A.; Ravez, J. Solid-State Chemistry and Non-Linear Properties of Tetragonal Tungsten Bronzes Materials. C.R. Chim. 2006, 9, 1268-1276. https://doi.org/10.1016/j.crci.2006.04.001. Josse, M.; Bidault, O.; Roulland, F.; Castel, E.; Simon, A.; Michau, D.; Von der Muehll, R.; Nguyen, O.; Maglione, M. The $\mathrm{Ba}_{2} \mathrm{LnFeNb}_{4} \mathrm{O}_{15}$ "Tetragonal Tungsten Bronze": Towards RT Composite Multiferroics. Solid State Sci. 2009, 11, 1118-1123. https://doi.org/10.1016/j.solidstatesciences.2009.02.015.

(12) Brik, F.; Enjalbert, R.; Roucau, C.; Galy, J. TTB Structure of $\mathrm{K}_{4} \mathrm{Ce}_{2} \mathrm{M}_{10} \mathrm{O}_{30}$ (M=Nb or Ta): Crystal Growth and Joint X-Ray and HREM Studies. J. Solid State Chem. 1996, 122, 7-14. https://doi.org/10.1006/jssc.1996.0073.

(13) Miseki, Y.; Kudo, A. Water Splitting over New Niobate Photocatalysts with Tungsten-Bronze-Type Structure and Effect of Transition Metal-Doping. Chemsuschem 2011, 4, 245-251. https://doi.org/10.1002/cssc.201000180.

(14) Yao, Y. B.; Mak, C. L.; Ploss, B. Phase Transitions and Electrical Characterizations of $\left(\mathrm{K}_{0.5} \mathrm{Na}_{0.5}\right)_{2 \times}\left(\mathrm{Sr}_{0.6} \mathrm{Ba}_{0.4}\right)_{5-\mathrm{x}} \mathrm{Nb}_{10} \mathrm{O}_{30}$ (KNSBN) Ceramics with 'unfilled' and 'filled' Tetragonal TungstenBronze (TTB) Crystal Structure. J. Eur. Ceram. Soc. 2012, 32, 4353-4361. https://doi.org/10.1016/j.jeurceramsoc.2012.07.034.

(15) Lin, K.; You, L.; Li, Q.; Chen, J.; Deng, J.; Xing, X. Thermal Expansion Anomaly in TTB Ferroelectrics: The Interplay between Framework Structure and Electric Polarization. Inorg. Chem. 2016, 55, 8130-8139. https://doi.org/10.1021/acs.inorgchem.6b01242.

(16) Zhu, X.; Fu, M.; Stennett, M. C.; Vilarinho, P. M.; Levin, I.; Randall, C. A.; Gardner, J.; Morrison, F. D.; Reaney, I. M. A Crystal-Chemical Framework for Relaxor versus Normal Ferroelectric Behavior in Tetragonal Tungsten Bronzes. Chem. Mater. 2015, 27, 3250-3261. https://doi.org/10.1021/acs.chemmater.5b00072.

(17) Simon, Q.; Dorcet, V.; Boullay, P.; Demange, V.; Députier, S.; Bouquet, V.; Guilloux-Viry, M. Nanorods of Potassium Tantalum Niobate Tetragonal Tungsten Bronze Phase Grown by Pulsed Laser Deposition. Chem. Mater. 2013, 25, 2793-2802. https://doi.org/10.1021/cm401018k.

(18) Rousseau, A.; Laur, V.; Deputier, S.; Bouquet, V.; Guilloux-Viry, M.; Tanne, G.; Laurent, P.; Huret, F.; Perrin, A. Influence of Substrate on the Pulsed Laser Deposition Growth and Microwave Behaviour of $\mathrm{KTa}_{0.6} \mathrm{Nb}_{0.4} \mathrm{O}_{3}$ Potassium Tantalate Niobate Ferroelectric Thin Films. Thin Solid Films 2008, 516, 4882-4888. https://doi.org/10.1016/j.tsf.2007.09.029.

(19) Boulle, A. DxTools: Processing Large Data Files Recorded with the Bruker D8 Diffractometer. J. Appl. Crystallogr. 2017, 50, 967-974. https://doi.org/10.1107/S1600576717005192. 
(20) Willmott, P. Deposition of Complex Multielemental Thin Films. Prog. Surf. Sci. 2004, 76, 163-217. https://doi.org/10.1016/j.progsurf.2004.06.001.

(21) Ma, C.; Chen, C. Pulsed Laser Deposition for Complex Oxide Thin Film and Nanostructure. In Advanced Nano Deposition Methods; John Wiley \& Sons, Ltd, 2016; pp 1-31. https://doi.org/10.1002/9783527696406.ch1.

(22) Jia, C. L.; Schubert, J.; Heeg, T.; Mi, S. B.; Chen, H. Y.; Joschko, B.; Burianek, M.; Muhlberg, M.; Urban, K. Tailoring the Orientations of Complex Niobate Films on Perovskite Substrates. Acta Mater. 2006, 54, 2383-2391. https://doi.org/10.1016/j.actamat.2006.01.011.

(23) Infortuna, A.; Muralt, P.; Cantoni, M.; Setter, N. Epitaxial Growth of (SrBa) $\mathrm{Nb}_{2} \mathrm{O}_{6}$ Thin Films on $\mathrm{SrTiO}_{3}$ Single Crystal Substrate. J. Appl. Phys. 2006, 100, 104110. https://doi.org/10.1063/1.2372577.

(24) Ebina, Y.; Higuchi, T.; Hattori, T.; Tsukamoto, T. Ferroelectric and Structural Properties of $\mathrm{Sr}_{0.5} \mathrm{Ba}_{0.5} \mathrm{Nb}_{2} \mathrm{O}_{6}$ Thin Films on $\mathrm{La}_{0.05} \mathrm{Sr}_{0.95} \mathrm{TiO}_{3}$ Substrate. Jpn. J. Appl. Phys. 2006, 45, 7300-7304. https://doi.org/10.1143/JJAP.45.7300.

(25) Debnath, T.; Roy, S. C.; Ruescher, C. H.; Hussain, A. Synthesis and Characterization of NiobiumDoped Potassium Tetragonal Tungsten Bronzes, $\mathrm{K}_{\mathrm{x}} \mathrm{Nb}_{\mathrm{y}} \mathrm{W}_{1-\mathrm{y}} \mathrm{O}_{3}$. J. Mater. Sci. 2009, 44, 179-185. https://doi.org/10.1007/s10853-008-3101-4.

(26) Madaro, F.; Saeterli, R.; Tolchard, J. R.; Einarsrud, M.-A.; Holmestad, R.; Grande, T. Molten Salt Synthesis of $\mathrm{K}_{4} \mathrm{Nb}_{6} \mathrm{O}_{17}, \mathrm{~K}_{2} \mathrm{Nb}_{4} \mathrm{O}_{11}$ and $\mathrm{KNb}_{3} \mathrm{O}_{8}$ Crystals with Needle- or Plate-like Morphology. CrystEngComm 2011, 13, 1304-1313. https://doi.org/10.1039/c0ce00413h.

(27) Lan, C.; Gong, J.; Wang, Z.; Yang, S. Synthesis of $\mathrm{K}_{6} \mathrm{Ta}_{10.8} \mathrm{O}_{30}$ Nanowires by Molten Salt Technique. Mater. Sci. Eng. B. 2011, 176, 679-683. https://doi.org/10.1016/j.mseb.2011.02.004.

(28) Nishio, K.; Seki, N.; Thongrueng, J.; Watanabe, Y.; Tsuchiya, T. Preparation and Properties of Highly Oriented $\mathrm{Sr}_{0.3} \mathrm{Ba}_{0.7} \mathrm{Nb}_{2} \mathrm{O}_{6}$ Thin Films by a Sol-Gel Process. J. Sol-Gel Sci. Technol. 1999, 16, 37-45. https://doi.org/10.1023/A:1008709104118.

(29) Nishio, K.; Watanabe, Y.; Tsuchiya, T. Epitaxial Growth of $\mathrm{Sr}_{x} \mathrm{Ba}_{1-x} \mathrm{Nb}_{2} \mathrm{O}_{6}$ Thin Films Prepared from Sol-Gel Process. J. Sol-Gel Sci. Technol. 2003, 26, 245-250. https://doi.org/10.1023/A:1020707317411.

(30) Mi, S. B.; Ha, C. L.; Urban, K.; Heeg, T.; Schubert, J. Growth of $\mathrm{Ca}_{x} \mathrm{Ba}_{1-\mathrm{x}} \mathrm{Nb}_{2} \mathrm{O}_{6}$ Thin Films on $\mathrm{MgO}(100)$ by Pulsed Laser Deposition. J. Cryst. Growth 2006, 291, 243-248. https://doi.org/10.1016/j.jcrysgro.2006.02.039.

(31) Schwyn Thöny, S.; Youden, K.; Harris, J.; Hesselink, L. Growth of Epitaxial Strontium Barium Niobate Thin-Films by Pulsed-Laser Deposition. Appl. Phys. Lett. 1994, 65, 2018-2020.

(32) Tanaka, K.; Nakagawara, O.; Nakano, M.; Shimuta, T.; Tabata, H.; Kawai, T. Epitaxial Growth of ( $\mathrm{Sr}, \mathrm{Ba}) \mathrm{Nb}_{2} \mathrm{O}_{6}$ Thin Films by Pulsed Laser Deposition. Jpn. J. Appl. Phys. 1998, 37, 6142-6145. https://doi.org/10.1143/JJAP.37.6142.

(33) Aoyagi, R.; Takeda, H.; Okamura, S.; Nishida, T.; Shiosaki, T. Epitaxial Growth of Tungsten Bronze $(\mathrm{Sr}, \mathrm{Ba}) \mathrm{Nb}_{2} \mathrm{O}_{6}$ Thin Films by Chemical Solution Deposition. In Proceedings of the $200112^{\text {th }}$ IEEE international symposium on applications of ferroelectrics, vols I and II; Streiffer, S. K., Gibbons, B. J., Tsurumi, T., Eds.; 2001; pp 905-908.

(34) Chiu, T. W.; Wakiya, N.; Shinozaki, K.; Mizutani, N. Growth of Highly (001)-Textured Strontium Barium Niobate Thin Films on Epitaxial $\mathrm{LaNiO}_{3} / \mathrm{CeO}_{2} / \mathrm{YSZ} / \mathrm{Si}(100)$. Thin Solid Films 2003, 426, 62 67. https://doi.org/10.1016/S0040-6090(02)01304-4.

(35) Cuniot-Ponsard, M.; Desvignes, J. M.; Ea-Kim, B.; Leroy, E. Radio Frequency Magnetron Sputtering Deposition of Hetero-Epitaxial Strontium Barium Niobate Thin Films $\left(\mathrm{Sr}_{x} \mathrm{Ba}_{1-x} \mathrm{Nb}_{2} \mathrm{O}_{6}\right)$. J. Appl. Phys. 2003, 93, 1718-1724. https://doi.org/10.1063/1.1535749. 
(36) Willmott, P. R.; Herger, R.; Patterson, B. D.; Windiks, R. Experimental and Theoretical Study of the Strong Dependence of the Microstructural Properties of $\mathrm{Sr}_{x} \mathrm{Ba}_{1-x} \mathrm{Nb}_{2} \mathrm{O}_{6}$ Thin Films as a Function of Their Composition. Phys. Rev. B 2005, 71, 144114. https://doi.org/10.1103/PhysRevB.71.144114.

(37) Ndione, P. F.; Gaidi, M.; Durand, C.; Chaker, M.; Morandotti, R.; Rioux, G. Structural and Optical Properties of Epitaxial $\mathrm{Ca}_{x} \mathrm{Ba}_{1-\mathrm{x}} \mathrm{Nb}_{2} \mathrm{O}_{6}$ Thin Films Grown on MgO by Pulsed Laser Deposition. J. Appl. Phys. 2008, 103, 033510. https://doi.org/10.1063/1.2838176.

(38) Zheleva, T.; Jagannadham, K.; Narayan, J. Epitaxial-Growth in Large-Lattice-Mismatch Systems. J. Appl. Phys. 1994, 75, 860-871. https://doi.org/10.1063/1.356440.

(39) Narayan, J.; Larson, B. C. Domain Epitaxy: A Unified Paradigm for Thin Film Growth. J. Appl. Phys. 2003, 93, 278-285. https://doi.org/10.1063/1.1528301.

(40) Zhang, K. H. L.; Lazarov, V. K.; Galindo, P. L.; Oropeza, F. E.; Payne, D. J.; Lai, H. H.-C.; Egdell, R. G. Domain Matching Epitaxial Growth of $\mathrm{In}_{2} \mathrm{O}_{3}$ Thin Films on Alpha- $\mathrm{Al}_{2} \mathrm{O}_{3}(0001)$. Cryst. Growth Des. 2012, 12, 1000-1007. https://doi.org/10.1021/cg201474h. 


\section{For Table of Contents Use Only}

Complex epitaxy of tetragonal tungsten bronze $\mathrm{K}-\mathrm{Ta}-\mathrm{Nb}-\mathrm{O}$ nanorods

V. Demange ${ }^{1,2^{*}}$, Q. Simon ${ }^{3}$, F. Gouttefangeas ${ }^{2}$, L. Joanny ${ }^{2}$, M. Guilloux-Viry ${ }^{1,2}$
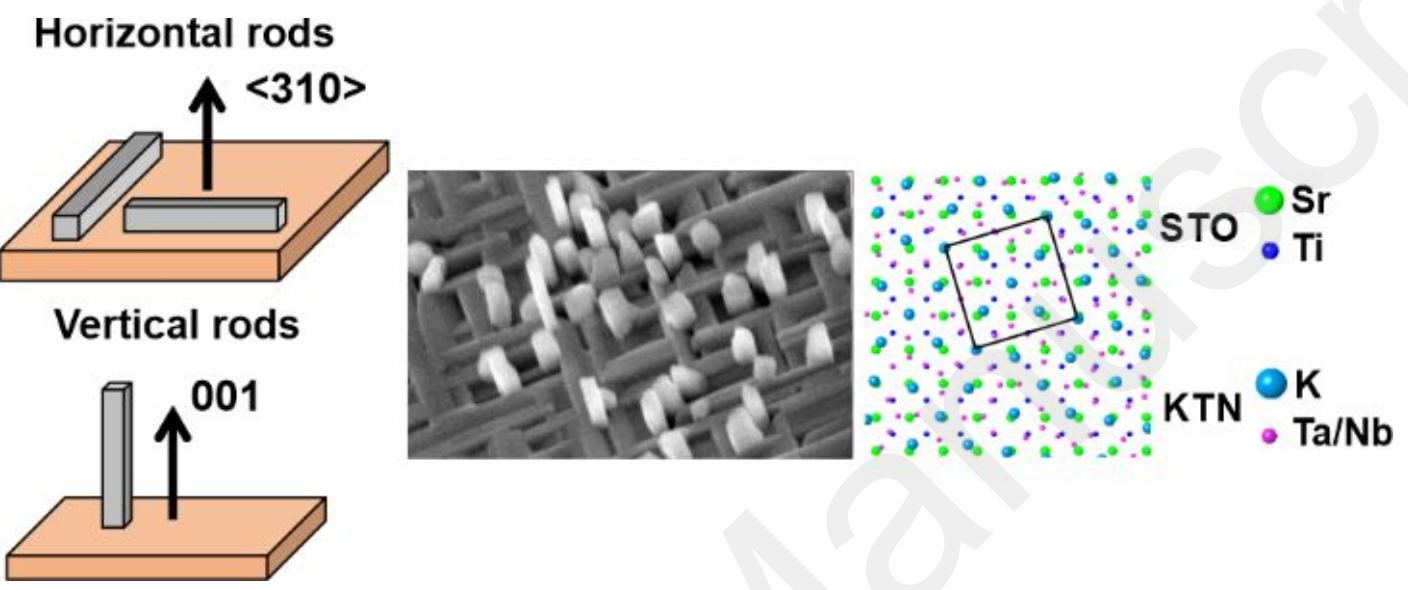

Growth of horizontal and vertical tetragonal tungsten bronze K-Ta-Nb-O nanorods on $\mathrm{SrTiO}_{3}$ 

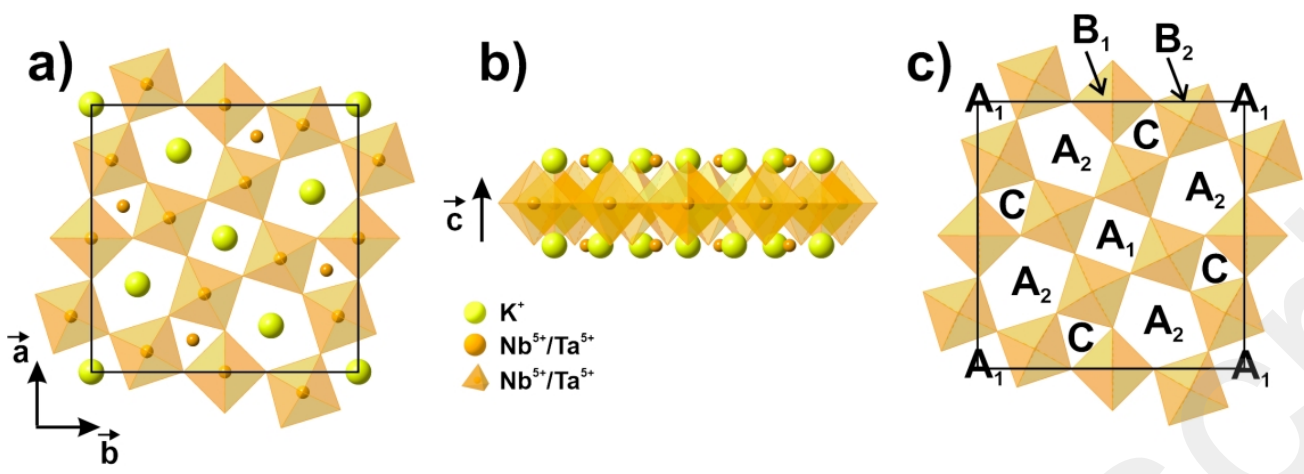

Figure 1. a) Projection of the KTN-TTB structure along the [001] direction. b) Projection of the TTB KTN structure along the [100] direction. c) Scheme of the TTB structure displaying the crystallographic sites. 


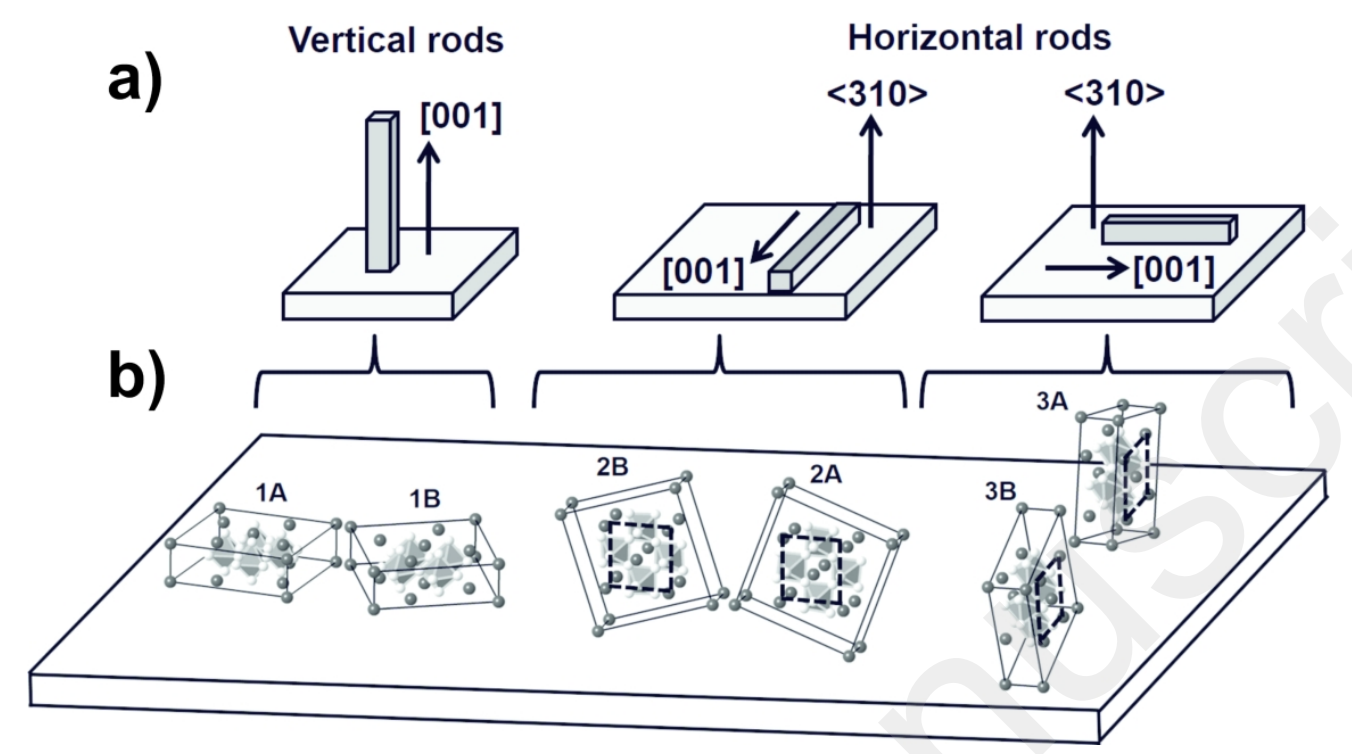

Figure 2. a) Scheme of the different orientations of the vertical and horizontal nanorods on the substrate. b) Scheme of all the possible orientations of the TTB phase on the substrate: on the left, vertical nanorods with two variants (labelled $1 \mathrm{~A}$ and $1 \mathrm{~B}$ ), and on the right, horizontal nanorods with four variants (labelled 2 to 3 ). 

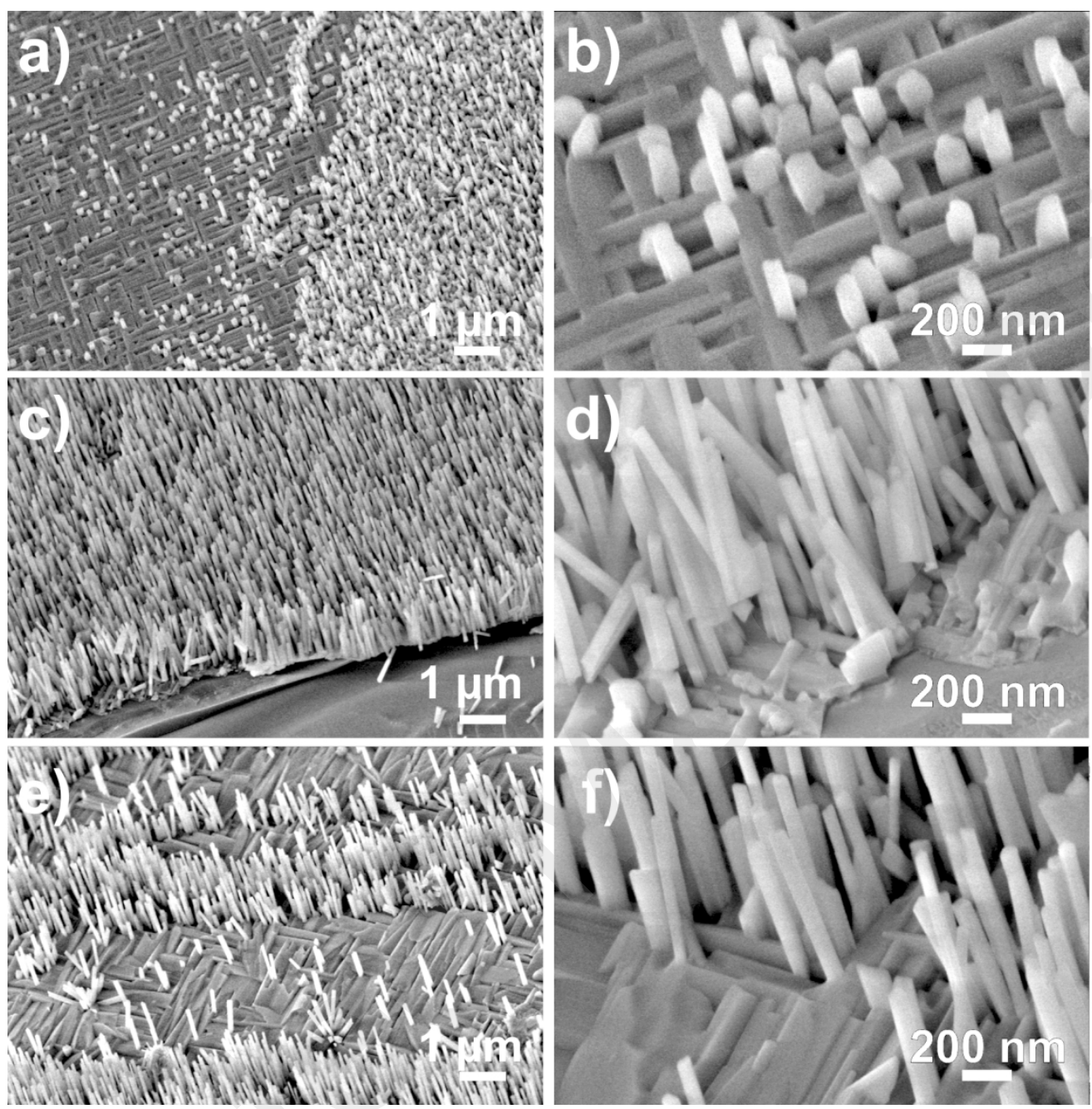

Figure 3. SEM micrographs at two different magnifications of KTN-TTB film deposited on (001)STO at $845^{\circ} \mathrm{C}$ $(\mathrm{a}, \mathrm{b})$, and of KTN-TTB films deposited on R-plane sapphire at $845^{\circ} \mathrm{C}(\mathrm{c}, \mathrm{d})$ and at $865^{\circ} \mathrm{C}(\mathrm{e}, \mathrm{f})$. 

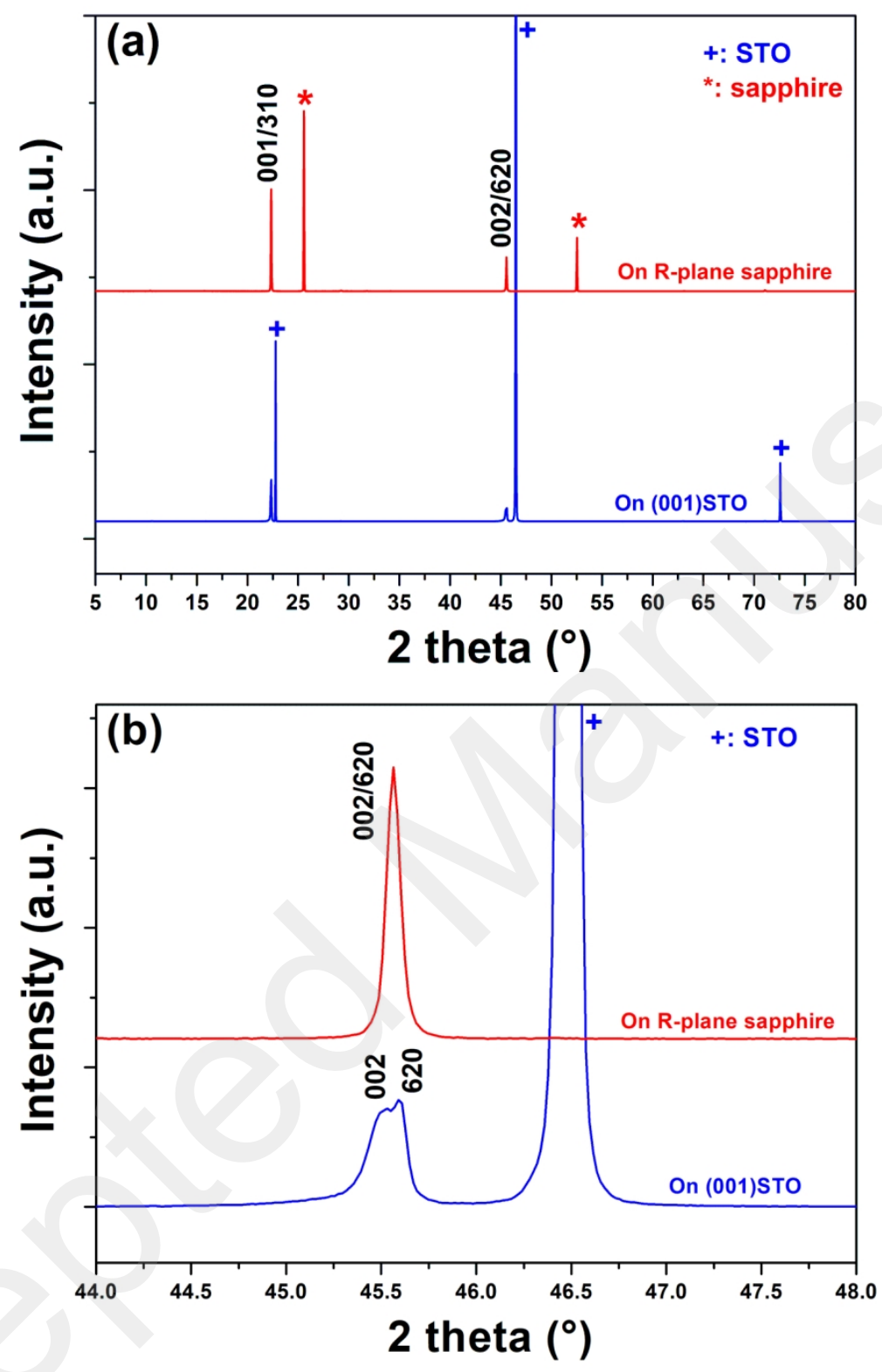

Figure 4. XRD patterns in $\theta / 2 \theta / 2$ mode of the KTN-TTB films deposited on (001)STO (blue curves) and on Rplane sapphire (red curves): a) full-scale patterns; b) same patterns in $2 \theta=44-48^{\circ}$ range. The peaks are indexed according to the TTB structure (+: STO; *: sapphire). 

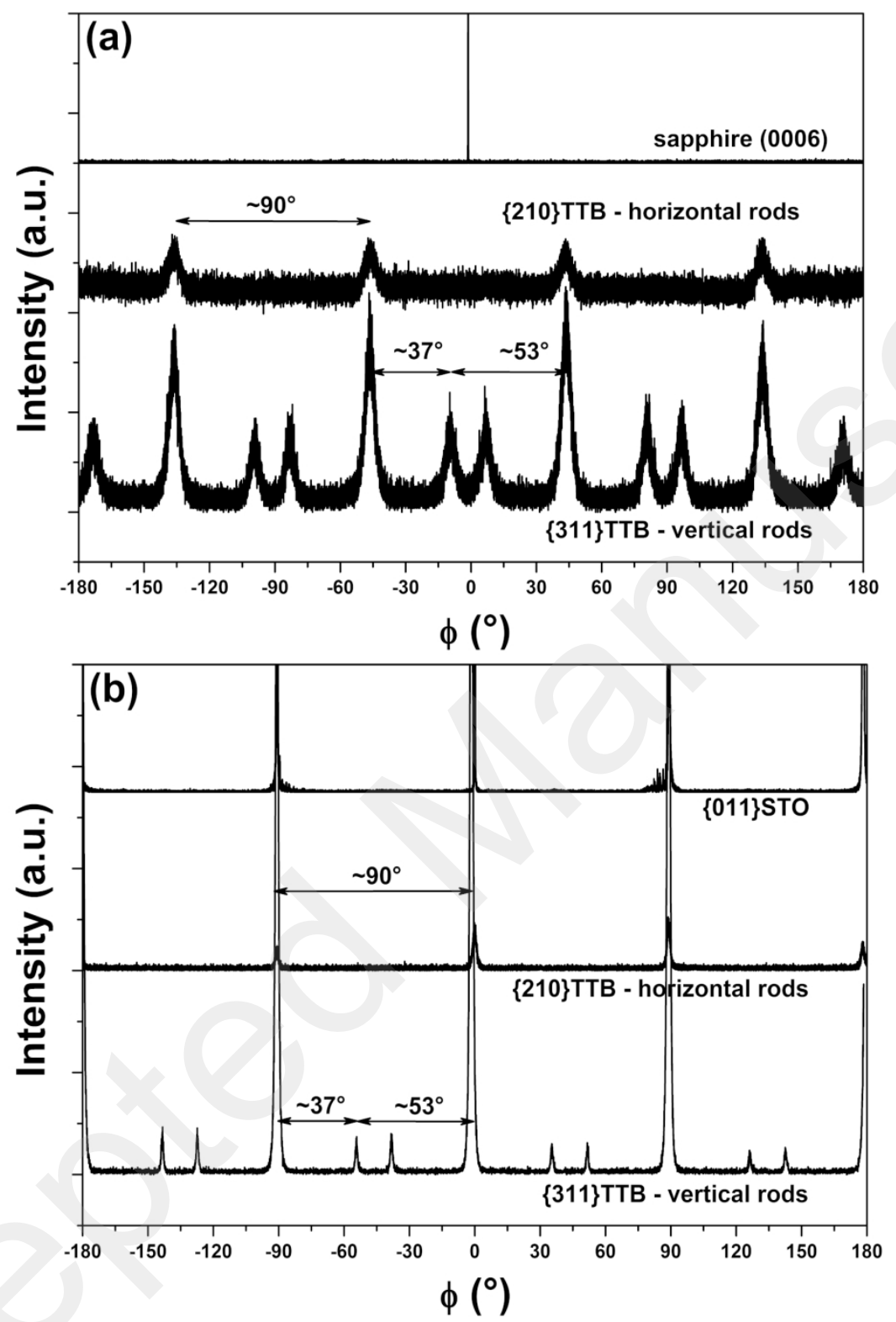

Figure 5. (a) Phi-scans of KTN/sapphire film, carried out on (0006) sapphire plane, \{210\}TTB planes of the horizontal nanorods, and \{311\}TTB planes of the vertical nanorods. (b) Phi-scans of KTN/STO film, carried out on $\{011\}$ STO planes, $\{210\}$ TTB planes of the horizontal nanorods, and $\{311\}$ TTB planes of the vertical nanorods. 


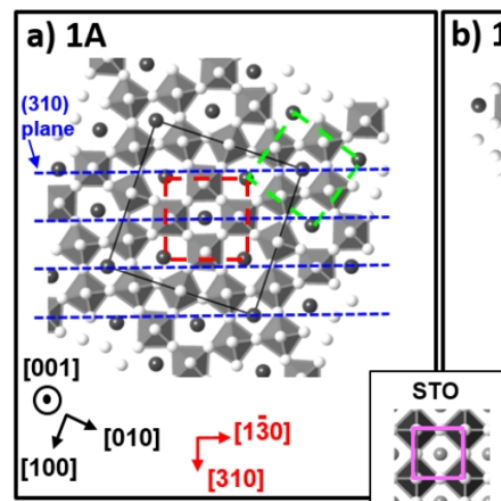

\section{b) $1 B$}
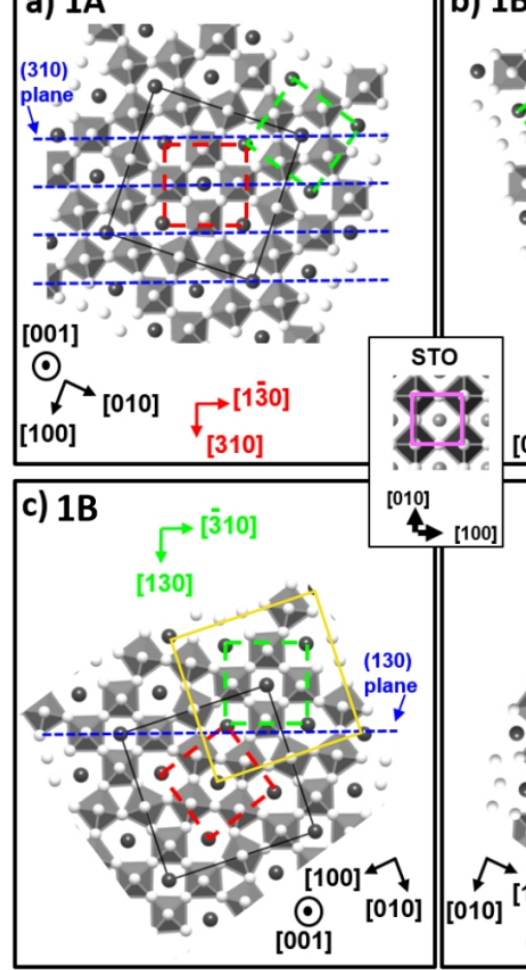

[100]

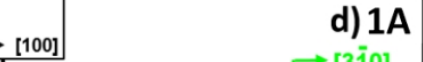

d) $1 \mathrm{~A}$
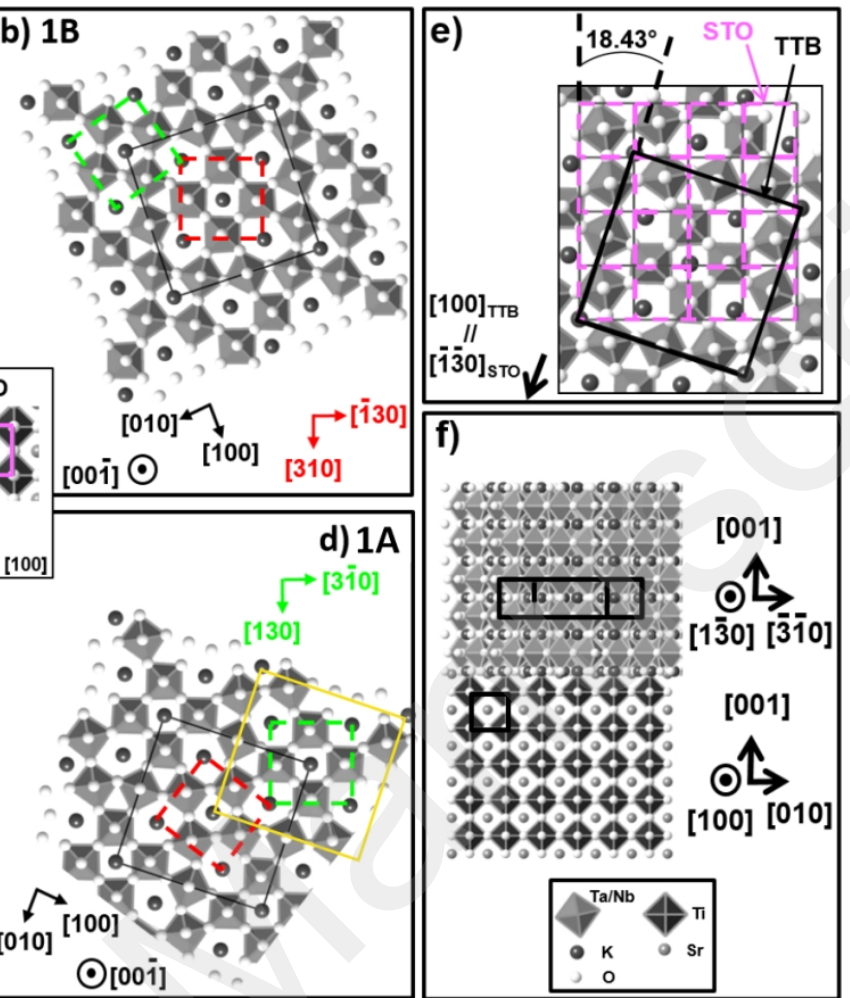

f)

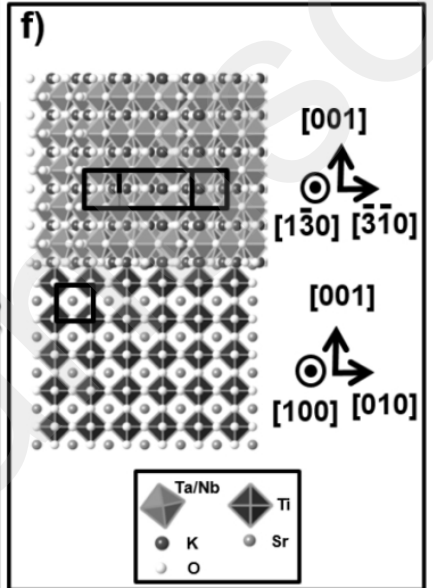

Figure 6. (a-d) Scheme of the two in-plane variants of the vertical nanorods on (001)STO, labelled $1 \mathrm{~A}$ and 1B. The TTB cell is drawn with black solid lines. The orientations $1 \mathrm{~A}(\mathrm{a})$ and $1 \mathrm{~B}$ (b) correspond to two antiphase domains related to each other by a vertical mirror plane. In these cases, the central sub-cell (red dashed lines) is parallel to the directions [100] and [010] of STO (STO cell is drawn in pink in the middle of the panel and in fig. 6e). c) Orientation $1 \mathrm{~A}$ after an in plane rotation of $+53.13^{\circ}$. The shift of the unit cell (black cell to yellow cell) shows that this orientation is identical to the orientation 1B displayed in fig. $6 \mathrm{~b}$. d) Orientation $1 \mathrm{~B}$ after an in plane rotation of $+36.87^{\circ}$. The shift of the unit cell (black cell to yellow cell) shows that this orientation is identical to the orientation 1A displayed in fig. 6a. (e) Superposition of the TTB phase on the STO lattice, showing the disorientation of $18.43^{\circ}$ between the two cells. (f) Scheme of the domain $1 \mathrm{~A}$ on STO in cross-sectional view. 

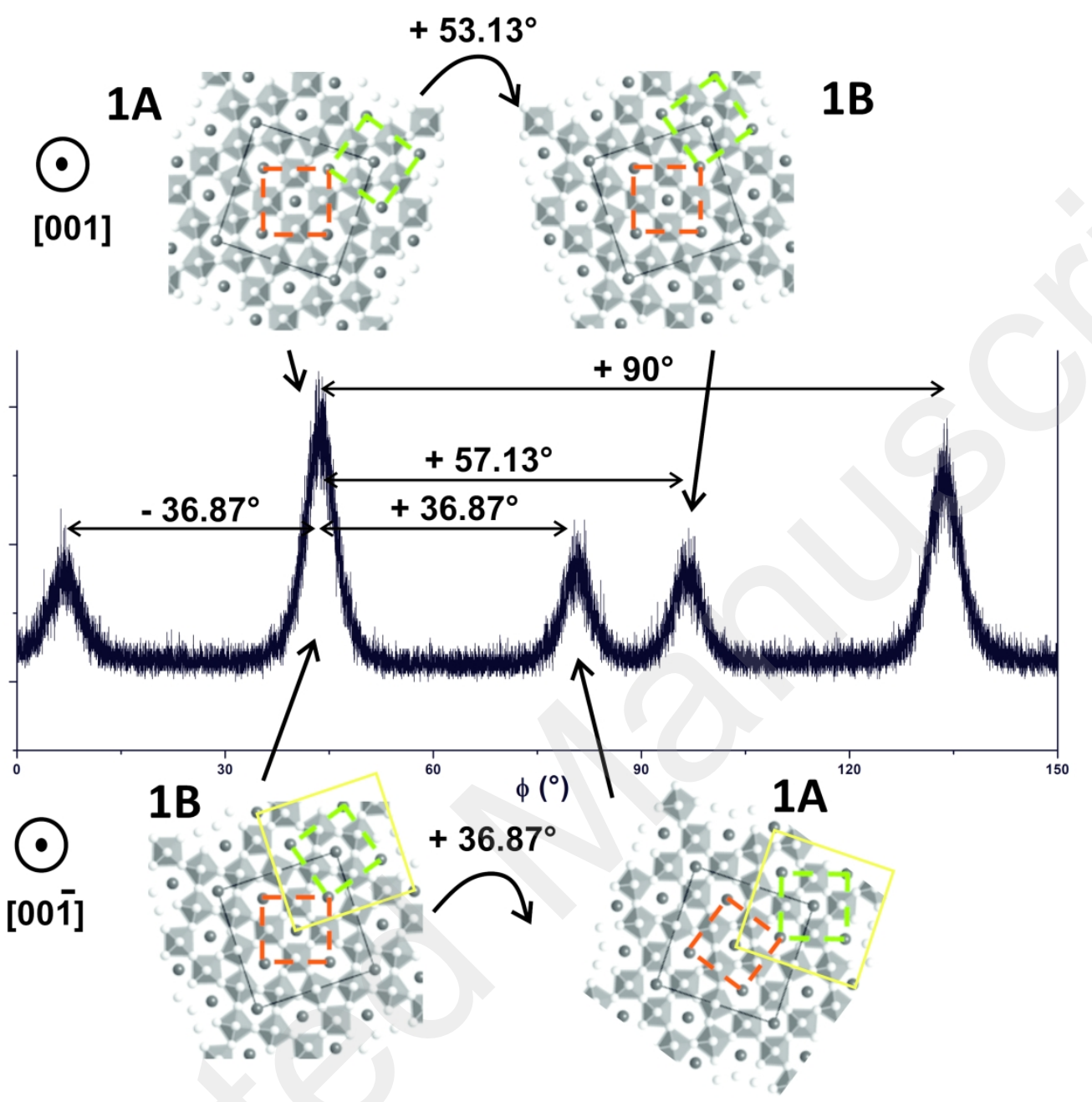

Figure 7. Occurrences of the different in-plane orientations of the vertical nanorods relatively to the experimental corresponding phi-scan around $\{311\}$ TTB planes. 


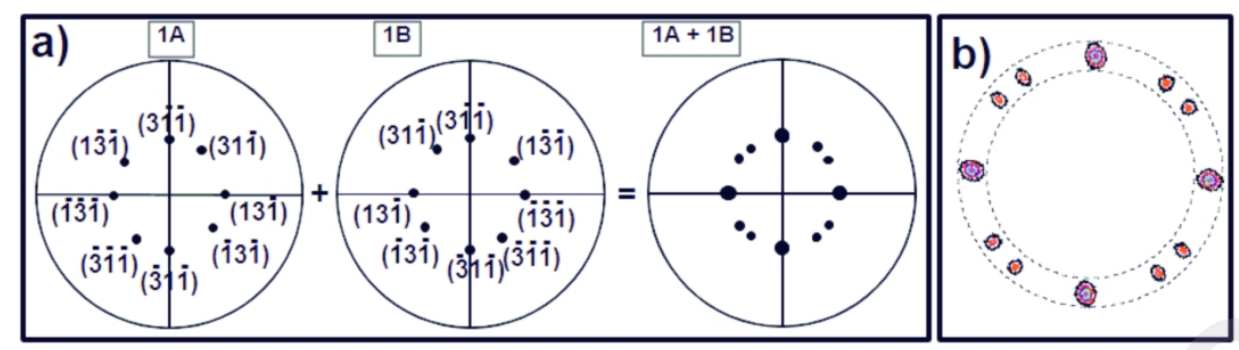

Figure 8. a) Modeling of $\{311\}$ pole figures of the TTB phase oriented along the domains $1 \mathrm{~A}$ and $1 \mathrm{~B}$, and superposition of the pole figures two by two. b) Experimental pole figure of $\{311\}$ planes of the vertical nanorods. 


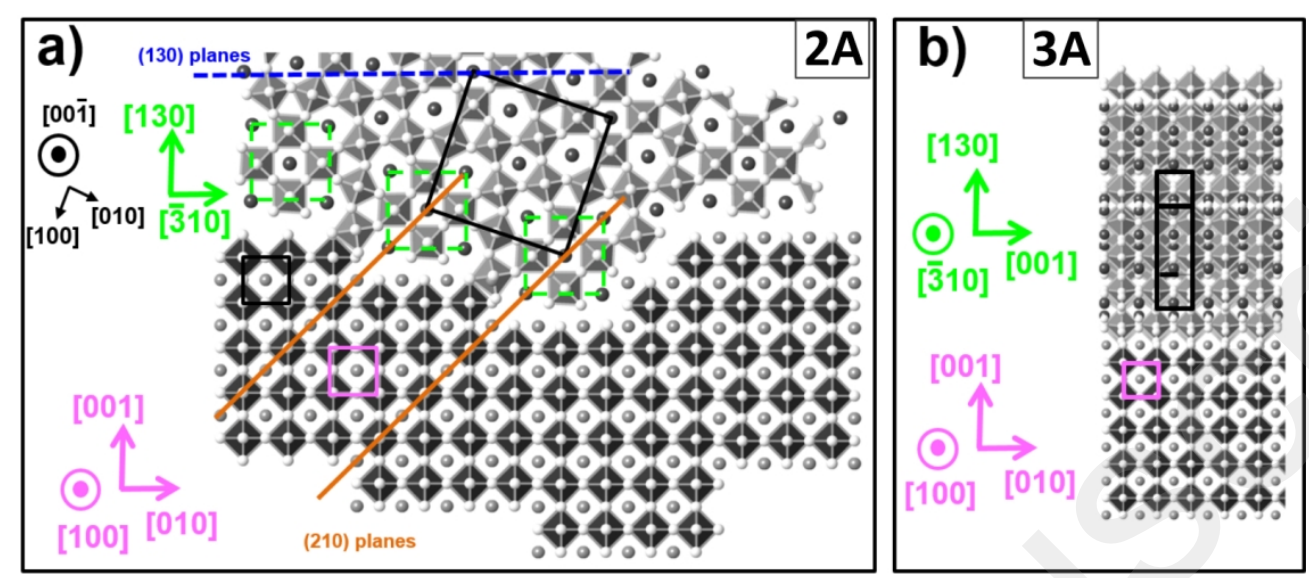

Figure 9. Modeling of the orientation of horizontal nanorods (light grey) on (001)STO (dark grey) in crosssectional view: the variant $2 \mathrm{~A}(\mathrm{a})$ is equivalent to the variant $3 \mathrm{~A}(\mathrm{~b})$ by rotation of $90^{\circ}$ along the growth direction. 


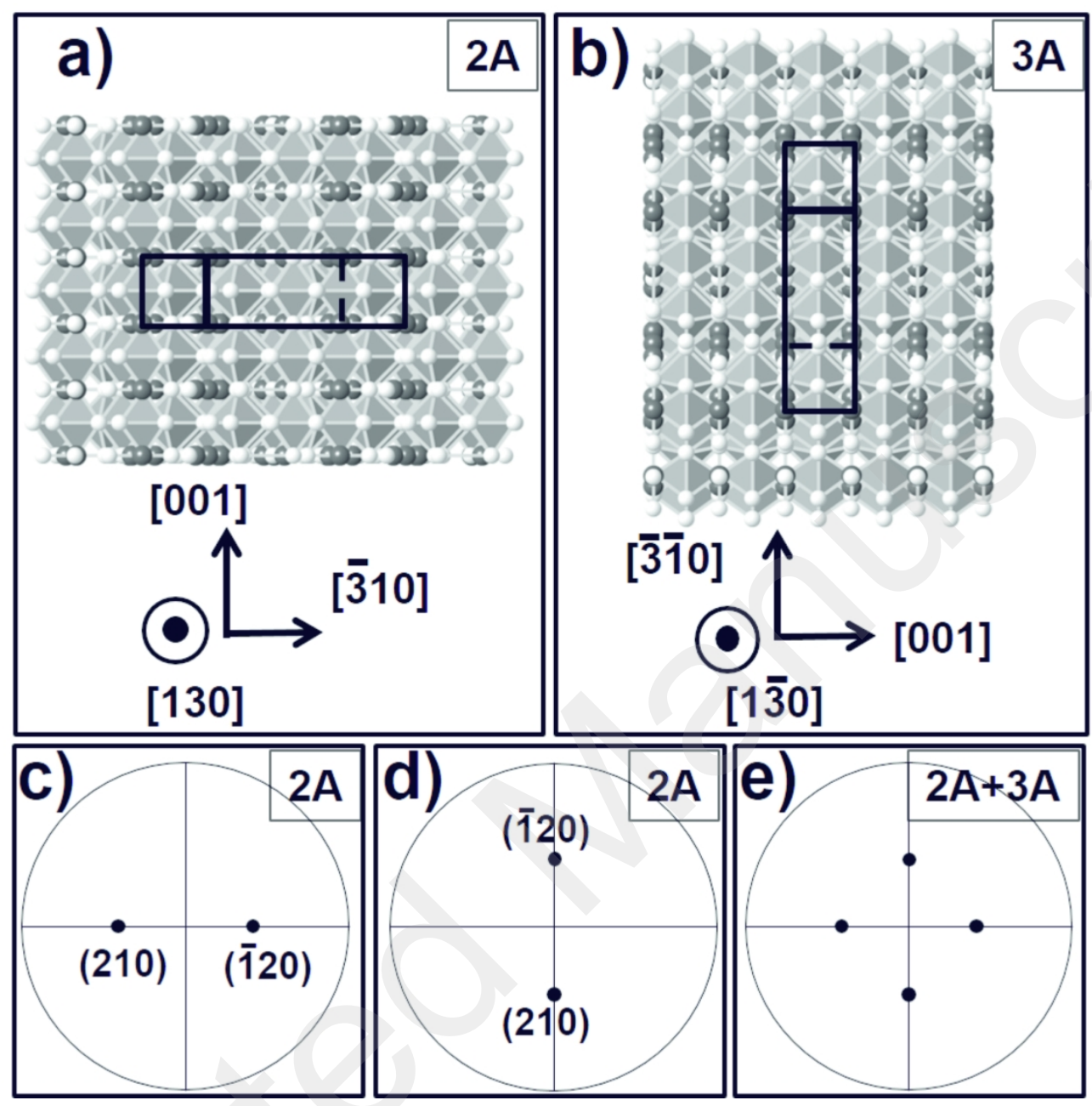

Figure 10. Modeling of the orientation of horizontal nanorods on (001)STO in plane-view (TTB cells are drawn with solid lines): the variant $2 \mathrm{~A}$ (a) is equivalent to the variant $3 \mathrm{~A}$ (b) by rotation of $90^{\circ}$ along the growth direction. Modeling of the pole figures of the TTB phase oriented along the domains $2 \mathrm{~A}$ (c) and $3 \mathrm{~A}$ (d) and superposition of both pole figures (e). 

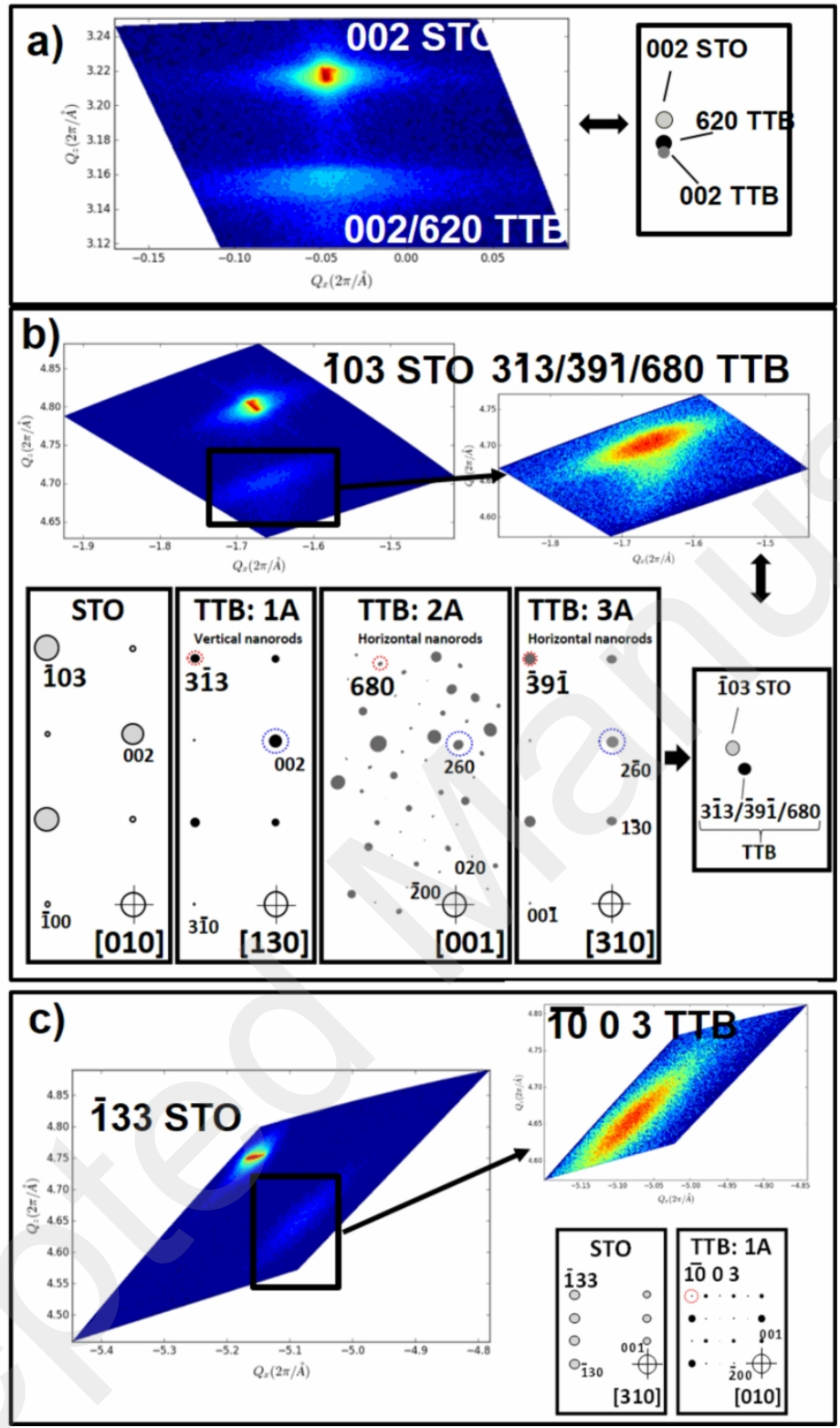

Figure 11. Reciprocal space maps of the KTN-TTB film on (001)STO: a) (002)STO RSM and corresponding scheme of the reciprocal space area. (b) (1 03)STO and (31 3)TTB RSMs and corresponding schemes of the reciprocal space areas. (c) (1 33)STO and ((10) 0 3)TTB RSMs and corresponding schemes of the reciprocal space areas. 

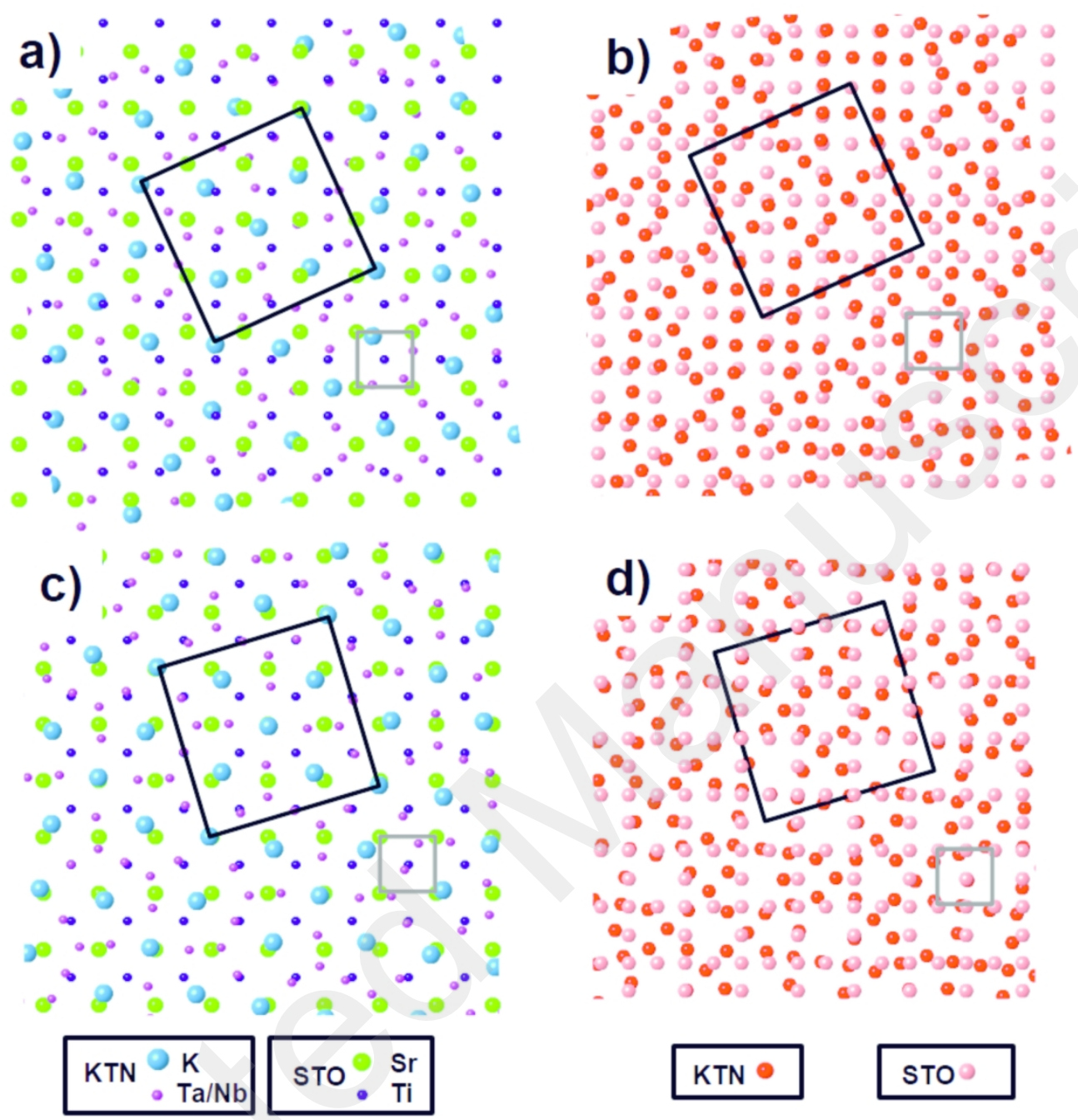

KTN •

STO

Figure 12. Superposition of the cationic (a) and anionic (b) lattices of the TTB and STO phases in the configuration in which (001) TTB perovskite sub-unit are aligned on (001) STO perovskite unit. Superposition of the cationic (c) and anionic (d) lattices of the TTB and STO phases with an in-plane disorientation of $18.43^{\circ}$ between both cells (cells are drawn with solid lines: TTB (dark, STO (grey)). 